\title{
Cutaneous and Muscle Afferents: Interactions with Potential Targets in vitro
}

\author{
C. Jeffery Woodbury and Sheryl A. Scott \\ Department of Neurobiology and Anatomy, University of Utah School of Medicine, Salt Lake City, Utah 84132
}

Previous studies suggest that cutaneous and muscle afferents use different environmental cues in growing to their peripheral targets. As a first approach to learning whether these earlier observations reflect differences in the behavior of individual growth cones, trigeminal cutaneous and muscle afferents of embryonic day 10 chicks were cocultured with explants of epidermis or dermis or with myotubes, and interactions of their growth cones with these potential targets were followed with time lapse video microscopy.

Cutaneous and muscle afferents differed in their response to all three targets. In birds, few cutaneous afferents innervate epidermis. Accordingly, most cutaneous neurites retracted within minutes of touching an epidermal cell. In contrast, most muscle afferents stopped growing but remained in contact with epidermis for as long as they were observed ( $>1 \mathrm{hr}$ ). Further, most cutaneous afferents grew readily across explants of dermis, their normal target, at rates comparable to their growth on the substrate. In contrast, most muscle afferents advanced only poorly on dermis. Finally, most cutaneous afferents grew readily across myotubes, the normal targets of muscle afferents. In contrast, few muscle afferents grew across myotubes; most either retracted or changed course and grew along the myotube. Overall, muscle afferents stayed in contact with myotubes longer than cutaneous afferents. These celltype-specific responses reflect in large part the patterns of cutaneous and muscle afferent growth in vivo. Further studies are required to determine whether these observed differences between the behavior of regenerating cutaneous and muscle afferent growth cones could potentially play a role in the selectlon of targets or pathways durlng embryonic development.

[Key words: trigeminal, sensory neuron, axon growth, skin, myotubes, chick, development, specificity]

During embryonic development sensory neurons in avian dorsal root ganglia (DRG) select axonal pathways and project to their peripheral targets with a high degree of precision (reviewed in

Received Aug. 12, 1994; revised Dec. 21, 1994; accepted Dec. 30, 1994.

We thank Ms. Kathryn Ann Fisher for technical assistance and Dr. Gary Schoenwolf for helpful comments on an earlier version of this manuscript. Some of the work reported here was carried out by S.A.S. in the Department of Neurobiology and Behavior, SUNY at Stony Brook. This work was supported by NIH NSI6067 to S.A.S.

Correspondence should be addressed to Sheryl A. Scott, Department of Neurobiology and Anatomy, University of Utah School of Medicine, 50 North Medical Drive, Salt Lake City, UT 84132.

Copyright $\mathcal{C} 1995$ Society for Neuroscience $0270-6474 / 95 / 153936-16 \$ 05.00 / 0$
Scott, 1992b). Work from several laboratories suggests that DRG ncurons that project to skin and to muscle use different environmental cues to select the pathways to their respective targets (Landmesser and Honig, 1986; Scott, 1988; Tosney and Hageman, 1989). It is not known, however, whether these earlier observations reflect the fact that sensory neurons have individual identities and different properties prior to axon outgrowth and contact with a target, which enable them to select the appropriate pathways and targets. Alternatively, sensory neurons could be nonspecifically channeled to skin and muscle, which subsequently determines their identity; that is, a nascent sensory neuron could have many potential targets. One approach to resolving this issue would be to ascertain whether there are differences in the behavior of cutaneous and muscle afferent growth cones that could account for the earlier findings, and to learn when during embryonic development such differences in growth cone behavior arise.

These questions are difficult to address for sensory ncurons in DRG because cutaneous and muscle afferents are intermixed within each ganglion (Honig, 1982) and are impossible to tell apart except by the target they innervate. In the avian trigeminal sensory system, however, cutaneous and muscle afferents are largely anatomically separate and can be readily isolated and grown in vitro. The dorsomedial pole of the trigeminal ganglion (DM-TG) consists primarily of neural crest-derived (D'AmicoMartel and Noden, 1983), NGF-dependent (Davies and Lindsay, 1984) cutaneous neurons (Noden, 1980), which appear to be homologous to cutaneous neurons in DRG. The trigeminal mesencephalic nucleus of birds (mesencephalic V, TMN) consists entirely of muscle afferents (Manni et al., 1965; Passatore et al., 1979; Hiscock and Straznicky, 1986), which are derived from precursors that share a common ancestry with the neural crest (Narayanan and Narayanan, 1978; Covell and Noden, 1989), and which are likely to be homologous to DRG muscle afferents.

In the present study, we followed the interactions of individual growth cones of embryonic DM-TG (cutaneous) and TMN (muscle) afferents with explants of epidermis and dermis and with myotubes in time lapse experiments. During normal development in birds, cutaneous axons ramify extensively in dermis, their usual target, but few axons enter the epidermis (Saxod, 1978); muscle afferents, in contrast, terminate among myotubes. We show here that there are differences in the behavior of growth cones of regenerating cutaneous and muscle afferents as they interact with these potential targets in vitro. Future studies will investigate whether such differences are also manifested during initial axon outgrowth and could potentially play a role in target or pathway selection during embryonic development.

Some of this work has been presented previously in abstract form (Scott, 1992a; Woodbury and Scott, 1994). 

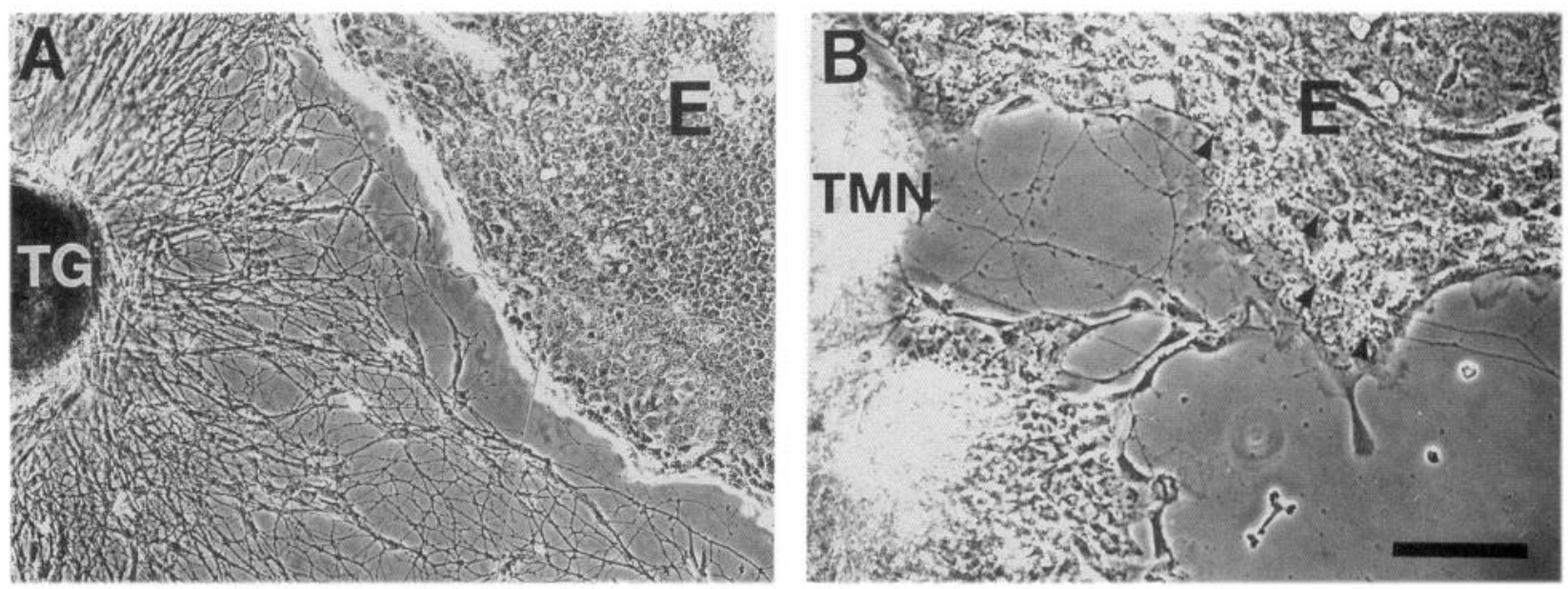

Figure 1. Cocultures of epidermis and trigeminal sensory neurons. (A) After $2 \mathrm{~d}$ in vitro cutaneous neurons from the dorsomedial trigeminal ganglion $(T G)$ appear to avoid epidermis $(E)$, making few contacts with the explant. $(B)$ In contrast, muscle afferents from the trigeminal mesencephalic nucleus $(T M N)$ maintain many contacts with the explant, and some neurites extend across the edge of the epidermis (arrowheads). Scale bar: $200 \mu \mathrm{m}$ for $A, 100 \mu \mathrm{m}$ for $B$.

\section{Materials and Methods}

Cultures. Embryos were from White Leghorn eggs incubated at $38^{\circ} \mathrm{C}$ in a forced-draft incubator and were staged according to Hamburger and Hamilton (1951). The dorsomedial pole of the trigeminal ganglion (DM-TG) or the medial division of the trigeminal mesencephalic nucleus (TMN) in the intertectal commissure was dissected from embryonic day 10 (E10; St. 36) embryos as described by Davies (1989), and cut into 5-10 small pieces. For simplicity, the DM-TG and TMN will be referred to here as cutaneous and muscle afferents, respectively, bearing in mind that each group may not be entirely homogeneous. Explants of neural tissue and either epidermis, dermis, or myotubes were cocultured in defined medium [F14 (GIBCO, Grand Island, NY)] supplemented either with additives as described by Bottenstein et al. (1980) or with N2 additives (GIBCO)] in glass-bottomed wells coated with poly-L-ornithine [Sigma, P-8638, St. Louis, MO $(0.5 \mathrm{mg} / \mathrm{ml}$ in $0.15 \mathrm{M}$ borate buffer, $\mathrm{pH} 8.5$, overnight at room temperature)] and laminin [GIBCO or Upstate Biotechnology, Inc., Lake Placid, NY $(20 \mu \mathrm{g} / \mathrm{ml}$ in $\mathrm{Ca}^{2+} / \mathrm{Mg}^{2+}$-free phosphate-buffered saline [PBS], for $4 \mathrm{hr}$ at $37^{\circ} \mathrm{C}$ )].

Dorsal skin from E7 (St.30) embryos was separated into epidermis and dermis according to the procedure of Verna (1985). Briefly, small pieces of skin were incubated for $5 \mathrm{~min}$ in $0.5 \%$ trypsin in PBS at $4^{\circ} \mathrm{C}$. The pieces were then transferred to media containing $10 \%$ horse serum, triturated gently with a fire-polished Pasteur pipette, and separated into epidermis and dermis with fine tungsten needles. These pieces were then cocultured with either DM-TG or TMN explants.

Myoblasts were isolated from pectoral or jaw adductor muscles (see Table 1) of E12 embryos according to Prives et al. (1987) and plated in complete medium [87\% D-MEM (GIBCO), 10\% horse serum, 2\% embryo extract and $1 \%$ penicillin/streptomycin] at initial densities of $2-6 \times 10^{5}$ myoblasts $/ \mathrm{ml}$. Myoblasts were initially confined to the center of the well by a Sylgard ring, which was removed after $1-2.5 \mathrm{hr}$. Two to $3 \mathrm{~d}$ later the complete medium was replaced with defined medium (F14/N2), and explants of either DM-TG or TMN were added around the island of myotubes.

Recordings and analysis. Time lapse recordings of interactions of individual growth cones with potential targets were made 16-32 $\mathrm{hr}$ after establishing cocultures. Culture dishes were filled with equilibrated F14/ $\mathrm{N} 2$ or defined medium, sealed with a glass slide, placed on the stage of an Olympus IMT2 inverted microscope, and viewed with a $40 \times$ phase objective. This stage was enclosed in a thermostatically controlled chamber that was maintained at $37^{\circ} \mathrm{C}$ throughout the recording session. Cultures were continuously viewed with low level light; although no filters were used, individual growth cones were routinely followed for several hours with no signs of phototoxicity. Images were captured every 15-30 sec with an SIT or CCD camera and recorded on a Panasonic optical memory disk recorder.

Neurites typically selected for study appeared to have had no previous contact with targets, were growing straight toward the targets, and their growth cones were at least $20 \mu \mathrm{m}$ (and usually about $50 \mu \mathrm{m}$ ) from the edge of the target at the beginning of the recording session. The length of neurites over time was measured from an arbitrary point on the images. In addition, the length of the neurite on the target was measured when it could be clearly discerned. Growth rates on the substrate were calculated by determining the total distance the neurite advanced during a $15-90 \mathrm{~min}$ period prior to its initial contact with the target; a few neurites were not observed for long enough prior to contact to calculate their growth rate on the substrate. Growth rates on the dermis were calculated by measuring the total distance the neurite advanced on the dermis during the recording session. Growth rates on myotubes were not determined because it was often impossible to resolve the fine processes of the growth cone on the surface of the myotube due to insufficient contrast. Therefore, a predicted crossing time for each neurite was calculated based on its growth rate on the substrate and the distance across the myotube along a straight line trajectory

Only the initial encounters between the growth cone and target were used for cataloging the responses of neurites. Because growth cones often collapsed and retracted when the parent neurite was contacted by another growth cone (e.g., Ivins and Pittman, 1989), neurites that collapsed when they were touched by another growth cone near the time they contacted an explant or myotube were excluded from further study. Also excluded were growth cones that failed to contact an explant or myotube during the time observed.

\section{Results}

The intent of the studies reported here was to compare the behavior of individual cutaneous and muscle afferent growth cones when they encountered different potential target tissues in vitro. Although there was variability in growth cone behavior for both types of neurons, overall there were striking differences between the responses of cutaneous and muscle afferents to all three targets.

\section{Interactions of neurites with epidermis}

In birds, the normal target of most cutaneous axons is the dermis. Few axons penetrate the epidermis (Saxod, 1978), suggesting that avian epidermis may be nonpermissive for sensory axon growth. In accord with this suggestion, explants of epidermis appeared to inhibit the growth of both cutaneous (DMTG) and muscle (TMN) afferents in vitro. Neurites extending over the epidermis were rare after $1-2 \mathrm{~d}$ in culture for both types of sensory neuron, as seen in Figure 1. However, the overall appearance of cutaneous and muscle afferent cocultures differed markedly at these times, indicating that the outcome of encounters of cutaneous afferent growth cones with epidermis was dif- 
ferent from that of muscle afferent growth cones. Fascicles of cutaneous axons coursed around the edge of the epidermis, making few contacts with the explant (Fig. 1A). In contrast, many contacts remained between muscle afferents and the epidermis, and muscle afferent neurites occasionally extended across a few epidermal cells, but never grew extensively over the explant (Fig. 1B).

Cutaneous (DM-TG) neurites. Time lapse observations of individual neurites confirmed that contact with the epidermis inhibited cutaneous neurite growth. Most cutaneous growth cones grew toward the epidermal explant at a steady rate, but collapsed and retracted rapidly upon touching an epidermal cell. Figure 2 illustrates typical interactions of two cutaneous neurites with epidermis. These two growth cones collapsed and retracted within minutes of contacting an epidermal cell, a behavior that both growth cones repeated several times during the recording session. Nearly one-third (6 of 20 ) of cutaneous growth cones retracted within $5 \mathrm{~min}$ of touching an epidermal cell, and threefourths retracted within $20 \mathrm{~min}$. Only one cutaneous growth cone did not retract during the time observed $(>60$ min after touching an epidermal cell). The outcomes of the initial encounters of all of the cutaneous growth cones with the epidermis are summarized in Figure $3 A$ and Table 1.

There were no obvious differences between the cutaneous growth cones that retracted very rapidly (within $10 \mathrm{~min}$ ) and the one that did not retract at all. For example, the growth rates of the neurites that retracted rapidly varied over a wide range (76 $\mu \mathrm{m} / \mathrm{hr}$ to $290 \mu \mathrm{m} / \mathrm{hr}$; average $135.4 \pm 81.6 \mu \mathrm{m} / \mathrm{hr}, n=9$ ); the growth rate of the one cutaneous neurite that did not retract fell in the middle of this range $(126 \mu \mathrm{m} / \mathrm{hr})$.

Muscle (TMN) afferents. Despite the persistence of contacts between neurites and epidermis, time lapse observations of individual neurites demonstrated that contact with epidermis also stopped muscle afferent growth. During recording sessions muscle afferents were seldom ( 1 of 24 ) seen to grow onto the epidermis. Unlike cutaneous neurites, however, muscle afferents seldom retracted upon encountering an epidermal cell. Figure 4 illustrates the bchavior of a typical muscle afferent growth cone, which collapsed upon touching the epidermis but did not retract, and was still in contact with the epidermis nearly an hour later.

The outcomes of the initial encounters of individual muscle afferent growth cones with epidermis are summarized in Figure $3 B$ and Table 1 . Half ( 12 of 24 ) of the muscle afferents did not retract during the time observed $(>60 \mathrm{~min}$ after contacting the epidermis). Those that did retract tended to stay in contact with the epidermis longer than did cutaneous afferents; for example, only one neurite retracted within $5 \mathrm{~min}$ of contact and only onefourth retracted within $20 \mathrm{~min}$. As with cutaneous afferents, the growth rates of muscle afferents on the substrate did not predict which growth cones would retract rapidly and which would remain in contact with the epidermis. Whereas the neurites that retracted rapidly (within $10 \mathrm{~min}$ ) advanced across the substrate more slowly $(54.4 \pm 13.7 \mu \mathrm{m} / \mathrm{hr}$; range 39 to $64 \mu \mathrm{m} / \mathrm{hr} ; n=$ 3 ) than those that did not retract $(110.4 \pm 45.5 \mu \mathrm{m} / \mathrm{hr}, n=9)$, their growth rates were within the range of the latter (32-202 $\mu \mathrm{m} / \mathrm{hr}$ ).

Other types of growth cone behavior. The overall appearance of cocultures of cutaneous neurons and epidermis suggested that growth cones might be avoiding the epidermis at a distance (cf. Verna, 1985; Verna et al., 1986), since fascicles of neurites coursed parallel to, but tens of micrometcrs away from, the explant edge (Fig. 1A). Despite this appearance, growth cones were rarely seen to turn away from the epidermis without first contacting the explant directly. In a few cases ( 2 of 20 ), however, a cutaneous neurite sprouted a lateral growth cone shortly after it touched the epidermis, then withdrew the original growth cone and grew off the explant in the direction of the new growth cone, as shown in Figure 5. Muscle affercnts also occasionally (2 of 24) exhibited the same type of behavior. Without time lapse observations, the resulting neurite trajectories might be mistakenly classified as representing avoidance of explants at a distance. It is unlikely, however, that we would have observed growth cones responding to gradients of a diffusible factor produced by the epidermis (Fichard et al., 1991; see also Pini, 1993), since we flooded the culture dishes prior to making time lapse observations.

\section{Interactions of neurites with dermis}

Cutaneous (DM-TG) neurites. The response of both cutaneous and muscle afferents to dermis, the usual target of cutaneous axons, differed from their response to epidermis. The appearance of cultures after 1-2 d suggested that cutaneous neurites grew readily on dermis, as a dense outgrowth of neurites extended across the explants. Time lapse observations of individual neurites confirmed this suggestion, as illustrated in Figure 6. Most cutaneous neurites grew readily onto the explant with little or no delay, although a few paused before venturing onto the dermis. However, once growth cones advanced onto the dermis, they grew at rates $(64.9 \pm 23.0 \mu \mathrm{m} / \mathrm{hr}, n=17)$ comparable to their growth on the substrate $(69.9 \pm 40.2 \mu \mathrm{m} / \mathrm{hr})$.

About une-fourth (6 of 25 ) of the cutaneous neurites did not advance onto the dermis, but instead retracted rapidly upon touching the explant, much like encounters with epidermis. Two additional growth cones advanced slightly onto the dermis, but subsequently retreated to the substrate. Prior to contacting the explant, there was no obvious difference between the neurites that retracted or retreated and those that progressed onto the dermis. For example, the former grew across the substrate at $76.4 \pm 16.4 \mu \mathrm{m} / \mathrm{hr}(n=8)$, rates comparable to those of the cutaneous neurites that extended onto the dermis (see above).

Muscle (TMN) afferents. In contrast to cutaneous neurites, growth cones of muscle afferents did not advance readily on dermis. After 1-2 d in vitro cocultures of dermis and muscle afferents were similar in appearance to cocultures of epidermis and muscle afferents, with neurites touching but rarely extending onto the explant.

Time lapse observations documented that muscle afferents did not grow well on dermis. Encountering dermis usually slowed the forward progress of muscle afferent growth cones. A few TMN neurites ( 3 of 26 ) retracted rapidly after contacting the dermis, but most grew onto the explant. However, many of these grew more slowly on the dermis than on the substrate, and most eventually retreated toward or onto the substrate. For example, the muscle afferent growth cone shown in Figure 7 advanced about $25 \mu \mathrm{m}$ onto the dermis and then withdrew to the substrate. The slower growth, coupled with eventual retreat, combined to significantly reduce the effective growth rate of TMN neurites on dermis $(34.7 \pm 34.9 \mu \mathrm{m} / \mathrm{hr})$ in comparison to their growth rate on the substrate $(67.7 \pm 38.8 \mu \mathrm{m} / \mathrm{hr}, n=17 ; p<0.015$, Wilcoxon signed rank test for paired values).

Comparison of cutaneous and muscle afferent response to dermis. The striking differences in the response of cutaneous and muscle afferent growth cones to dermis are summarized in Figure 8 and Table 1. Overall, more than $80 \%$ (21 of 26) of the 

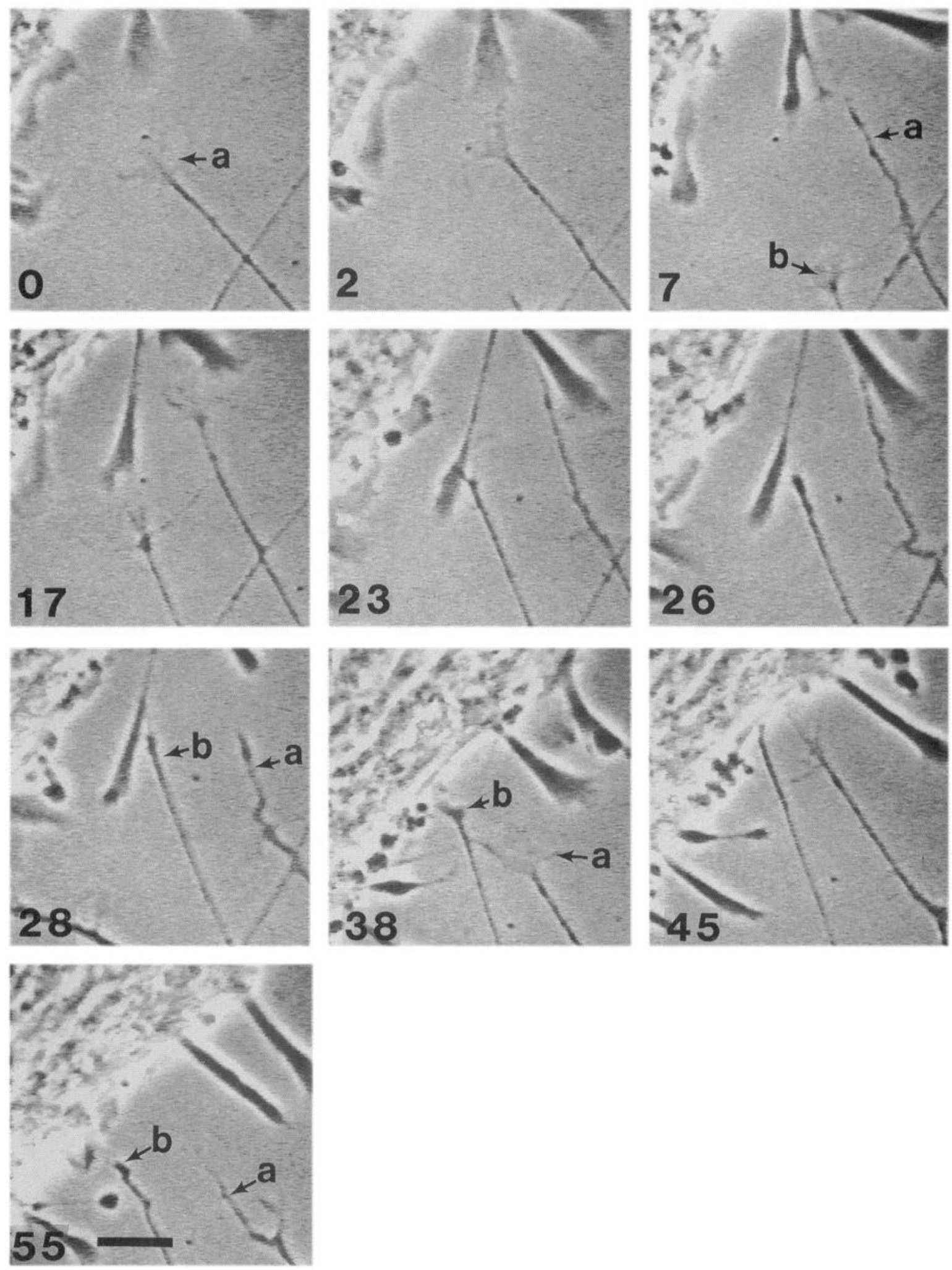

Figure 2. Time lapse records of interactions of DM-TG cutaneous neurites with epidermis. The number in each panel represents the time (min) at which the image was captured. One growth cone $(a)$ touches an epidermal cell $(t=2 \mathrm{~min})$ and rapidly retracts $(t=7 \mathrm{~min})$. It then regrows, touches and retracts two more times. A second growth cone $(b)$ touches and retracts twice during the same recording session. Note that the field of view is shifted slightly at $t=38 \mathrm{~min}$, but all panels show the same two neurites. Scale bar, $20 \mu \mathrm{m}$. 

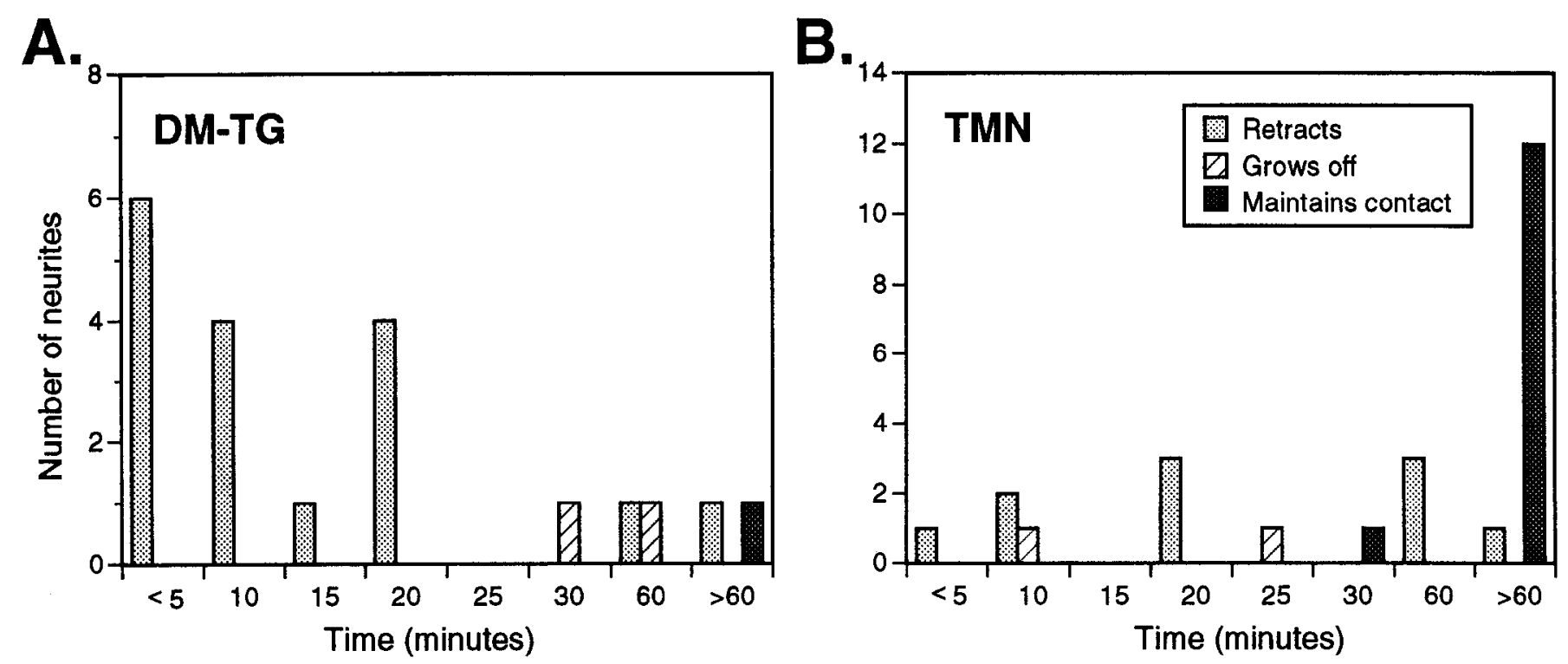

Figure 3. Bar graph summarizing the outcome of the initial encounters of $(A)$ cutaneous $(D M-T G)$ and $(B)$ muscle $(T M N)$ afferent growth cones with explants of epidermis. Each chart shows the length of time that different neurites remained in contact with the epidermis before retracting or growing off. Most cutaneous neurites retracted rapidly, while most muscle afferents did not retract during the time observed. Neurites scored as "grows off" touched the edge of the explant, then grew off in a new direction, as for example in Figure 5. For simplicity, only the highest time value of each bin is shown on the abscissa.

muscle atferents actually became shorter between the time they contacted the dermis and the end of the recording session, with nearly $60 \%$ ( 15 of 26 ) having retracted or retreated off the dermis when recording was stopped. By contrast, only $32 \%$ (8 of 25) of cutaneous neurites shortened under similar conditions, and only $28 \%$ ( 7 of 25 ) were not on the dermis at the end of the recording session.

To quantify further the differences between the response of $\mathrm{cu}$ taneous and muscle afferents to dermis, we calculated the length that each neurite would have grown after contacting the dennis if its growth continued at the same rate as on the substrate. TMN neurons that encountered dermis grew significantly less than predicted ( $p=0.0004$, Wilcoxon test). Whereas DM-TG neurites also grew less than predicted, they more closely approached their theoretical length $(p=0.03$ ), as illustrated in Figure 9.

None of these differences can be accounted for by differences in initial growth rate of the two populations of neurons, as both cutaneous and muscle afferents grew at the same rate on the substrate $(72.1 \pm 33.8 \mu \mathrm{m} / \mathrm{hr}$ and $73.6 \pm 40.5 \mu \mathrm{m} / \mathrm{hr}$, respectively). Together these results show that whereas cutaneous neurites generally grow readily on explants of dermis, muscle afferents do not.

\section{Interactions of neurites with myotubes}

To explore further the differences between cutaneous and muscle afferents, we studied their interactions with myotubes, the norInal targets of muscle afferents, in time lapse experiments. The myotubes used in initial studies were derived from pectoral muscle. However, because both motor and sensory components of the trigeminal system exhibit specificity for their appropriate targets during early embryonic development (Lumsden and Davies, 1983, 1986; Heaton and Wayne, 1986), we used myotubes derived from the adductor mandibulae muscle, the primary target of many avian TMN neurons (Wild and Zeigler, 1980; von Bartheld and Bothwell, 1993) in later experiments. As seen in Table 1 , the latter constitute the majority of interactions analyzed for both types of sensory afferents. Whereas slight quantitative dif- ferences were seen within both populations of sensory afferents, and especially among TMN neurites, to myotubes of different origin, these differences may be more apparent than real due to the small sample size of pectoral myotubes. Since the responses of both sensory neuron populations to myotubes of different origin were qualitatively similar (i.e., the same types of responses were exhibited by both populations of sensory afferents to each kind of myotube), the data were pooled for the following analyses.

After 16-24 hr in culture, the overall appearance of cocultures of myotubes and explants of cutaneous or muscle afferents was similar. In both types of coculture, for example, some myotubes were skirted by fascicles of neurites that streamed around them, as if the myotube had inhibited neurite growth. In contrast, many myotubes were crossed by neurites, while others had neurites growing along them, and thus appeared to be preferred by neurites over the substrate. However, quantitative distinctions were revealed between these two populations of afferents when individual neurites were followed in time lapse studies.

Cutaneous (DM-TG) neurites. The majority of cutaneous neurites (23 of 27 analyzed) appeared to largely ignore myotubes and grew across them with little or no change in trajectory, as illustrated in Figure 10. The growth cones of these neurites advanced readily onto the myotube with little delay and with a fully extended morphology; in no instance did any exhibit signs of collapse (e.g., Fig. 10). In contrast, the growth cones of iwo other cutaneous neurites collapsed after contact and retracted from the myotube (after 30 and $43 \mathrm{~min}$, respectively), while two others grew onto the myotube and remained in contact for the duration of the recording (65 and 113 minutes, respectively). Two additional neurites grew around the myotube after contacting it near one end; these were not analyzed further.

Despite the apparent homogeneity in response of cutaneous afferents, there was wide variation in the amount of time these neurites took to cross the myotube, as summarized in Figure 11A. As expected, crossing time was positively correlated with 
Table 1. Summary of percentages of responses of trigeminal sensory growth cones to potential targets

\begin{tabular}{|c|c|c|}
\hline & $\begin{array}{l}\text { Dorsomedial } \\
\text { trigeminal } \\
\text { ganglion }\end{array}$ & $\begin{array}{l}\text { Trigeminal } \\
\text { mesencephalic } \\
\text { nucleus }\end{array}$ \\
\hline \multicolumn{3}{|l|}{ Epidermis } \\
\hline Retracts/grows off & $95(19)$ & $50 \quad(12)$ \\
\hline Maintains contact & $5(1)$ & $50 \quad(12)$ \\
\hline \multicolumn{3}{|l|}{ Dermis } \\
\hline Retracts/shortens" & $32(8)$ & $80.8^{k}(21)$ \\
\hline Continuous growth & $68(17)$ & $7.7(2)$ \\
\hline \multicolumn{3}{|l|}{ Myotubes } \\
\hline \multicolumn{3}{|l|}{ Pectoral } \\
\hline Retracts $^{d}$ & $20(1)$ & $71.4(5)$ \\
\hline Grows across" & $60(3)$ & $14 \quad(1)$ \\
\hline Maintains contact & $20(1)$ & $14 \quad(1)$ \\
\hline \multicolumn{3}{|l|}{ Jaw adductors } \\
\hline Retracts & $4.5(1)$ & $43 \quad(9)$ \\
\hline Grows across & $91(20)$ & $33 \quad(7)$ \\
\hline Maintains contact & $4.5(1)$ & $24 \quad(5)$ \\
\hline \multicolumn{3}{|l|}{ Total } \\
\hline Retracts & $7.4(2)$ & $50 \quad(14)$ \\
\hline Grows across & $85(23)$ & $29 \quad(8)$ \\
\hline Maintains contact & $7.4(2)$ & $21 \quad(6)$ \\
\hline
\end{tabular}

Boldface responses indicate interactions with "appropriate" targets. Numbers in parentheses indicate number of growth cones observed.

"Most growth cones in this category collapsed and retracted without growing onto epidermis; a few turned and grew away after contact. For more details, see text.

"Growth cones either retracted without advancing onto dermis, or extended onto dermis, but subsequently became shorter.

- Growth cones grew on dermis without shortening or retracting, and remained on dermis throughout the recording session.

"Growth cones collapsed and retracted.

'Growth cones crossed the myotube and resumed growth on the substrate.

Growth cones (or in a few cases filopodia) were in contact with a myotube throughout the recording session.

s Three other growth cones did not grow onto dermis (2) or grew across dermis onto the substrate.

myotube width ( $p=0.004$, Kendall's correlation coefficient), but not with the neurite's prior growth rate on the substrate $(p$ $=0.90$ ). Thus, most of the variability in crossing time can be accounted for by differences in the width of the myotube.

In an attempt to quantify better the affect of myotubes on neurite growth rate, we calculated a delay value for cach neurite as the difference between the observed crossing time and that which was predicted based upon the neurite's previous growth rate along a straight line trajectory across the myotube; the alternative, an accurate measurement of growth rate on the myotube, was frequently impossible (see Materials and Methods). Neurites varied widely in the amount of time they were delayed by the myotube, and most took longer to cross than predicted, although a few appeared to increase their growth rates on the myotube. However, these calculated delay values (average = $13.3 \pm 23.7 \mathrm{~min}$; range $=-17$ to $96 \mathrm{~min}$ ) were not correlated with any obvious variable, such as myotube width or a neurite's previous growth rate on the substrate.

Muscle (TMN) afferents. Surprisingly, the responses of muscle afferents to myotubes were more diverse than observed with cutaneous afferents. Half of all muscle afferents retracted after contacting a myotube, and the rest either crossed or remained in contact throughout the recording session. These responses are summarized in Figure $11 B$ and Table 1, and described in more detail below.

In contrast to cutaneous afferents, relatively few (8 of 28) muscle afferents crossed a myotube, but like cutaneous afferents, those that did (such as the growth cone illustrated in Fig. 12) varied in the amount of time they took to cross. Unlike cutaneous afferents, however, this time was not significantly correlated with myotube width $(p=0.06)$, suggesting that muscle and cutaneous afferents that crossed may have responded differently to the myotubes encountered, although the average delays calculated for both populations were nearly identical (13.5 $\pm 20.9 \mathrm{~min}$, range $=-2$ to $58 \mathrm{~min}$ for $\mathrm{TMN}$ ).

As indicated above, half of all muscle afferents (14 of 28) retracted after encountering a myotube; an example is shown in Figure 12. These neurites varied widely in the amount of time they were in contact with a myotube before retracting (range $=$ 1-171 min; Fig. 11B). For example, half of these neurites retracted relatively quickly, in less than $20 \mathrm{~min}$ (average $=8.7 \pm 5.6$ min); the growth cones of some of these collapsed and retracted after establishing no more than a few highly dynamic filopodial contacts. In contrast, half of these neurites stayed in contact much longer ( $\geq 30 \mathrm{~min}$, average $=82.6 \pm 53.9$ ), and most ( 6 of 7) were in contact for longer than 45 minutes; for many of these, the growth cones advanced repeatedly onto the myotube before finally collapsing and retracting. Interestingly, TMN neurites appeared to retract more frequently (Table 1) and relatively more quickly (not shown) from pectoral compared to jaw myotubes; although additional data are needed, these findings suggest that TMN neurites, like trigeminal motoneurons (e.g., Heaton and Wayne, 1986), differ in their response to myotubes of different origin (cf. Copray and I iem, 1993), and thus may be able to recognize distinctions between appropriate and inappropriate targets.

More than one-fifth ( 6 of 28 ) of all muscle afferents maintained contact with a myotube throughout the recording session, $1-2.5 \mathrm{hr}$ after initial contact (average $=112.2 \pm 31.6 \mathrm{~min} ; n$ $=6$ ). These neurites typically changed course after contact and grew onto or along the edge of the myotube, as illustrated in Figure 13, some at rates that approached their growth rates on the substrate. Most grew in close apposition to the myotube (e.g., Fig. 13), although one "walked" along the edge of the myotube, contacting it only through dynamic filopodia.

There was no obvious difference between muscle afferents that could be used to predict their behavior. For example, whereas the growth rates of muscle afferents that retracted from myotubes were faster on average $(87.1 \pm 55.1 \mu \mathrm{m} / \mathrm{hr}, n=14)$ than either those that crossed $(55.3 \pm 33.2 \mu \mathrm{m} / \mathrm{hr}, n=8)$ or remained in contact $(54.5 \pm 27.9 \mu \mathrm{m} / \mathrm{hr}, n=6)$, these differences were not significant ( $p>0.1$, Mann-Whitney $U$ test).

Comparison of cutaneous and muscle afferent response to myotubes. To quantify the effects of myotubes on neurite growth we calculated the length that each neurite would have grown after contacting the myotube if its growth continued at the same rate as on the substrate. As illustrated in Figure 14, muscle afferents grew significantly less than predicted $(p<0.0001$; Wilcoxon test), whereas cutaneous afferents more closely approached their theoretical length $(p=0.02)$. This difference is not simply due to the fact that more muscle afferents than cutaneous afferents retracted (i.e., shortened) after contacting a myotube, since similar results were obtained $(p=0.04$ and 0.006 for cutaneous and muscle afferents, respectively) cven when all neurites that had retracted were excluded from this analysis. Instead, this difference 

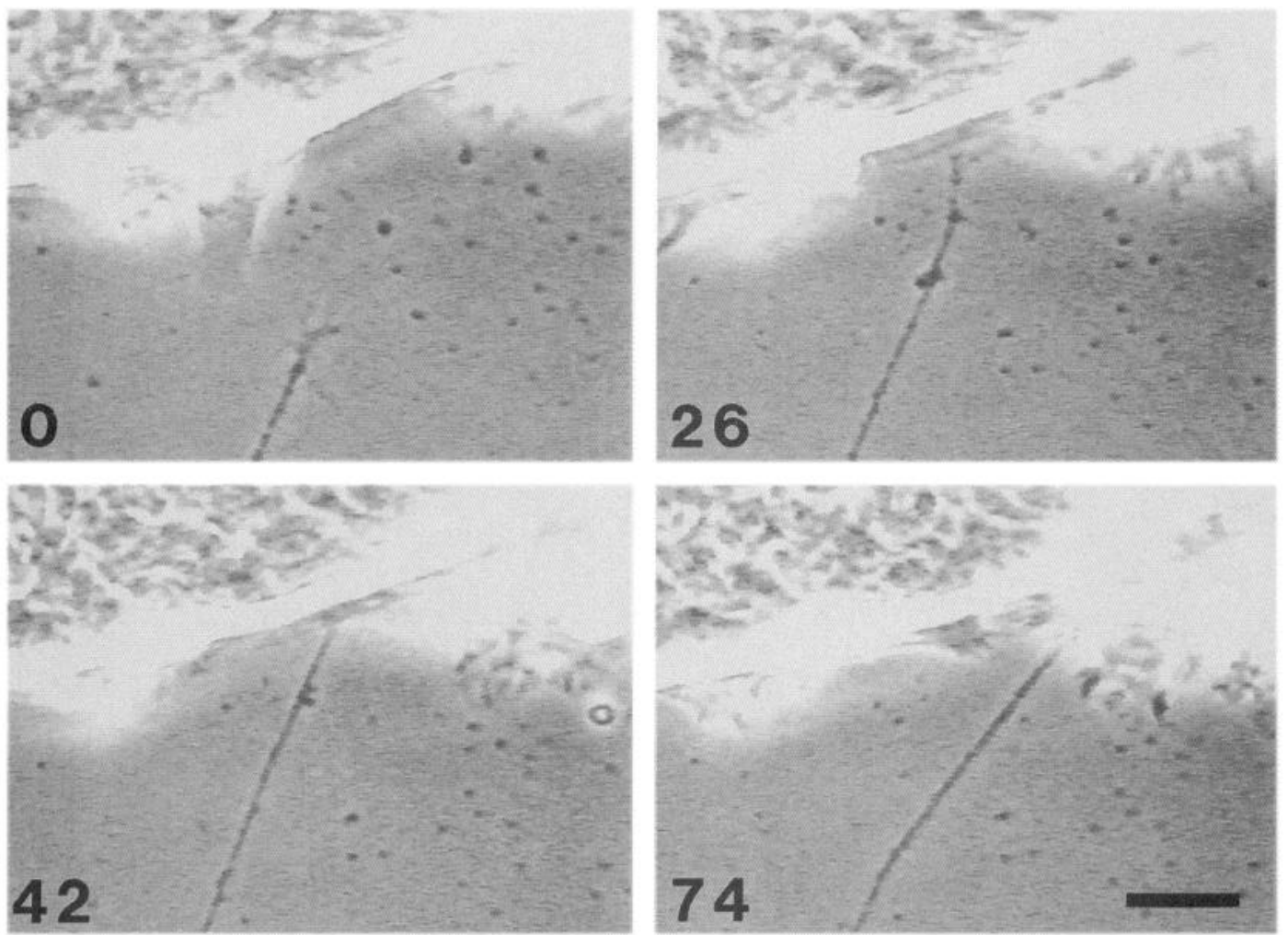

Figure 4. Time lapse records of an encounter of the growth cone of a TMN muscle afferent with an explant of epidermis. The muscle afferent growth cone collapsed upon touching the explant, but did not retract. It was still in contact with the dermis nearly an hour later, having been towed along by the epidermis. The number in each panel represents the time $(\mathrm{min})$ at which the image was captured. Scale bar, $20 \mu \mathrm{m}$.
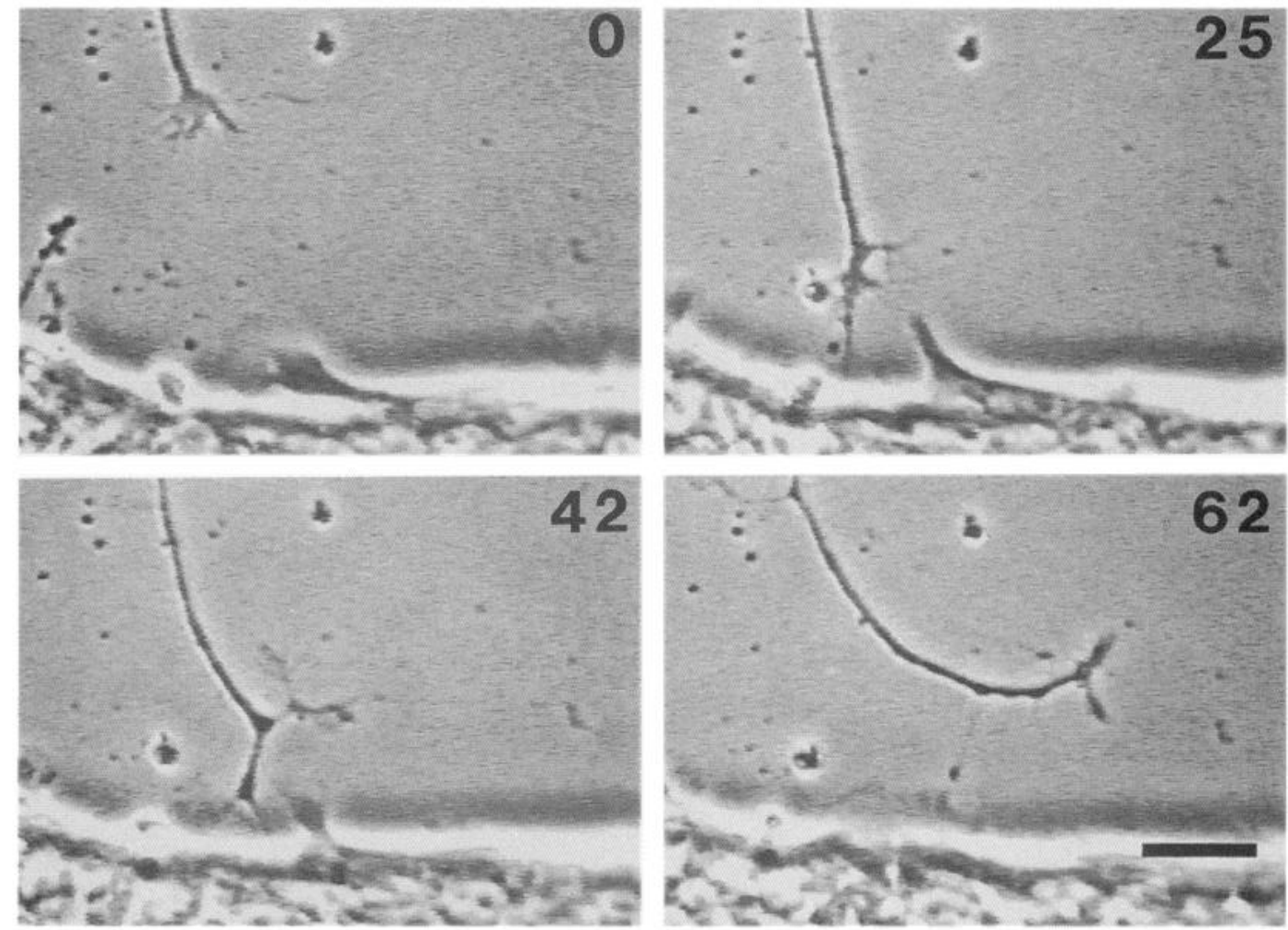

Figure 5. Time lapse records of an encounter of a DM-TG cutaneous neurite with epidermis. The neurite sprouted a lateral growth cone, withdrew the original one and grew off in the direction of the new growth cone. The number in each panel represents the time (min) at which the image was captured. Scale bar, $20 \mu \mathrm{m}$. 

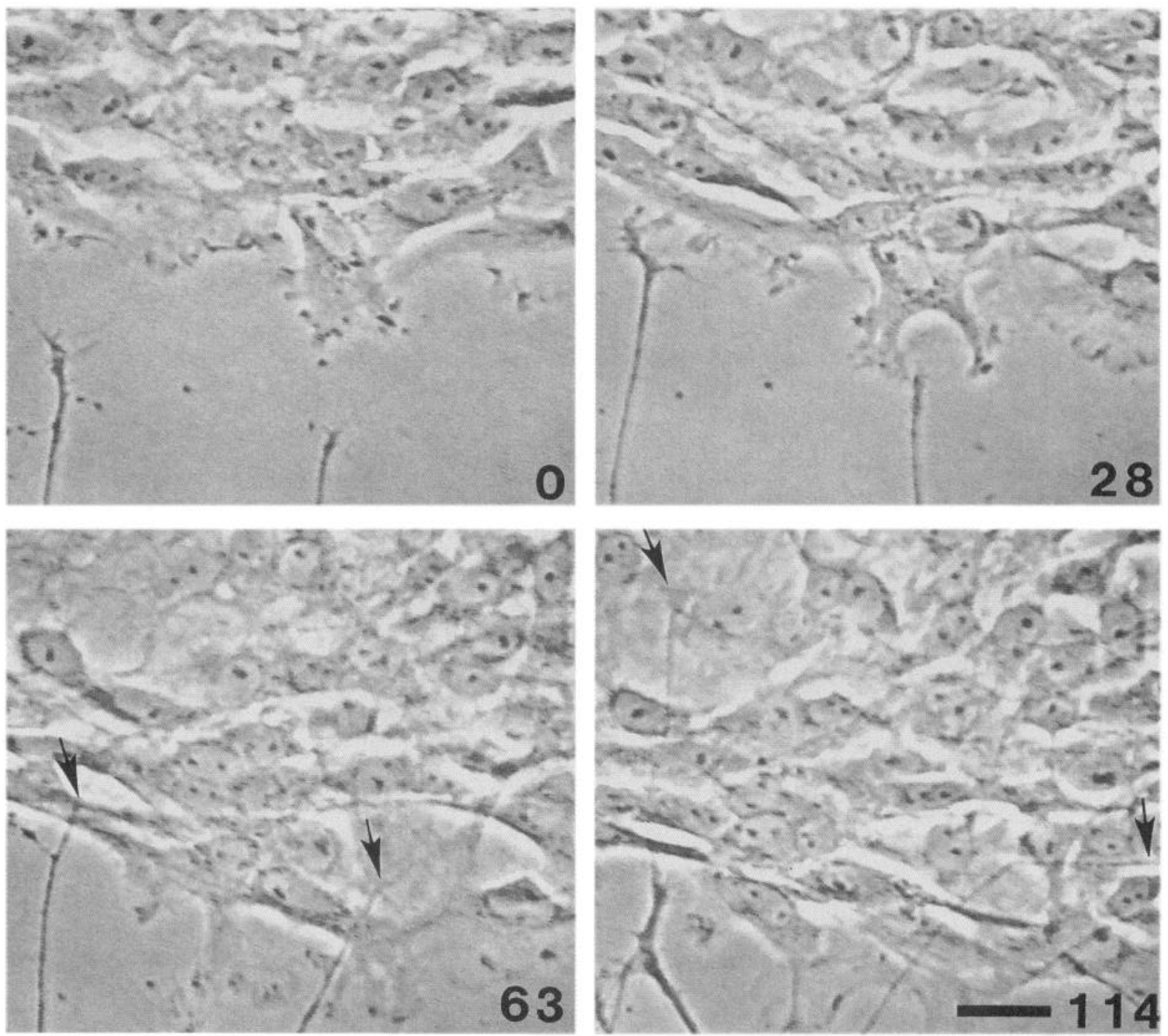

Figure 6. Time lapse records of encounters of cutaneous neurons from the DM-TG with explants of dermis. The two neurites grew readily onto the dermis with little delay. Arrows point to the tips of the neurites. Note the large flattened growth cone of the neurite on the left in the last panel. The number in each panel represents the time $(\mathrm{min})$ at which the image was captured. Scale bar, $20 \mu \mathrm{m}$.

reflects the fact that, overall, muscle afferent growth cones remained in contact with myotubes longer than cutaneous afferent growth cones. For example, after $60 \mathrm{~min}, 39 \%$ of muscle afferents were still in contact with a myotube as opposed to $19 \%$ of cutaneous afferents. This difference became even more pronounced after 90 minutes, when $25 \%$ of muscle afferents were still in contact compared to only $7 \%$ of cutaneous afferents. This difference could not be accounted for by any obvious difference between the populations of muscle and cutaneous afferents. For example, although cutaneous afferents in these experiments grew slightly slower on the substrate on average $(62.0 \pm 25.4 \mu \mathrm{m} / \mathrm{hr}$; $n=27)$ than muscle afferents $(70.5 \pm 43.9 \mu \mathrm{m} / \mathrm{hr} ; n=28)$, this difference was not significant. The longer contact times of TMN neurites with myotubes, coupled with their more diverse responses, suggest that these muscle afferents may be responding to information on the myotube surface that is either ignored or not detected by cutaneous neurites.

\section{Discussion}

The goal of the present studies was to compare the behavior of cutaneous (DM-TG) and muscle (TMN) afferent growth cones in defined situations in vitro to look for differences that may be involved in normal development. We found that trigeminal cutaneous and muscle afferents differed markedly in their response to three potential targets - epidermis, dermis, and myotubes. $\mathrm{Cu}$ taneous neurites collapsed and quickly retracted upon contact with epidermis, but grew readily across dermis and myotubes. In contrast, muscle afferents stopped growing but did not retract after contacting epidermis; most grew onto dermis but subsequently retreated. The response of muscle afferents to myotubes was more varied; half of all muscle afferents either grew across or turned to grow along the myotube, whereas the other half collapsed and retracted. Overall, muscle afferents remained in contact with myotubes longer than cutaneous afferents. The observed differences between the behavior of these two sensory populations in response to potential targets suggest that there are likely to be differences among their growth cones that could play a role in the selection of axonal pathways or targets during embryonic development or axonal regeneration.

\section{Interactions with skin explants}

Our observations that most trigeminal cutaneous neurites retracted rapidly upon encountering epidermis, but grew readily across 

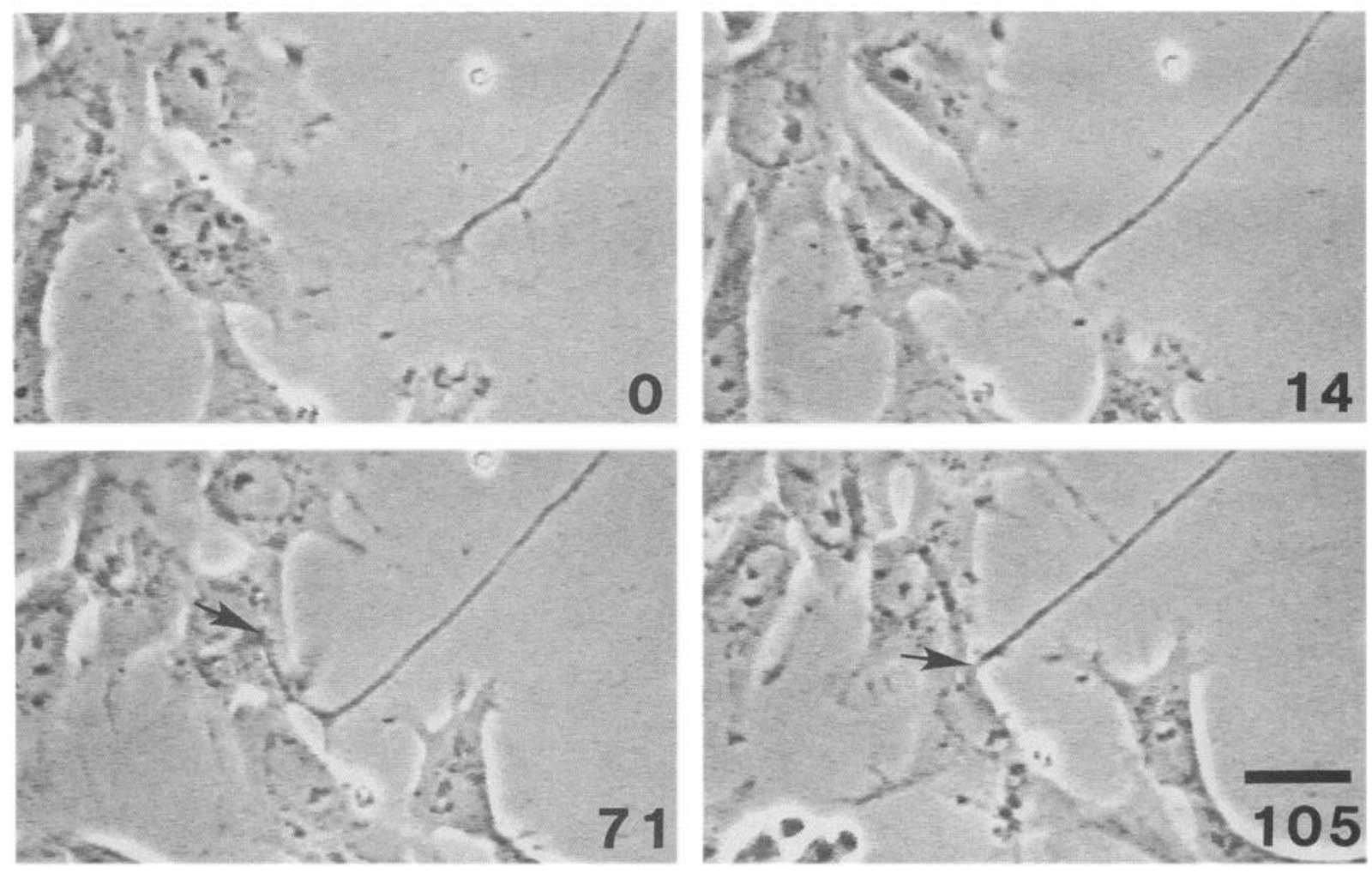

Figure 7. Time lapse records of an encounter of a TMN muscle afferent neurite with an explant of dermis. The neurite advanced about $25 \mu \mathrm{m}$ onto the dermis and then withdrew; this retreat represented a gradual shortening of the neurite, rather than a rapid retraction. Arrow indicates the tip of the neurite. The number in each panel represents the time $(\mathrm{min})$ at which the image was captured. Scale bar, $20 \mu \mathrm{m}$.

dermis, are superficially similar to previously reported interactions of dorsal root ganglion (DRG) neurites with epidermis and dermis (Verna, 1985; Verna et al., 1986). However, there are several significant differences. First, most DRG neurites turned away from epidermis at a distance, without directly contacting the explant, as if responding to a diffusible cue, a behavior seldom seen in the present experiments. Second, most trigeminal muscle afferents did not retract upon encountering epidermis and did not advance well over dermis, behaviors that were not observed among DRG neurites.
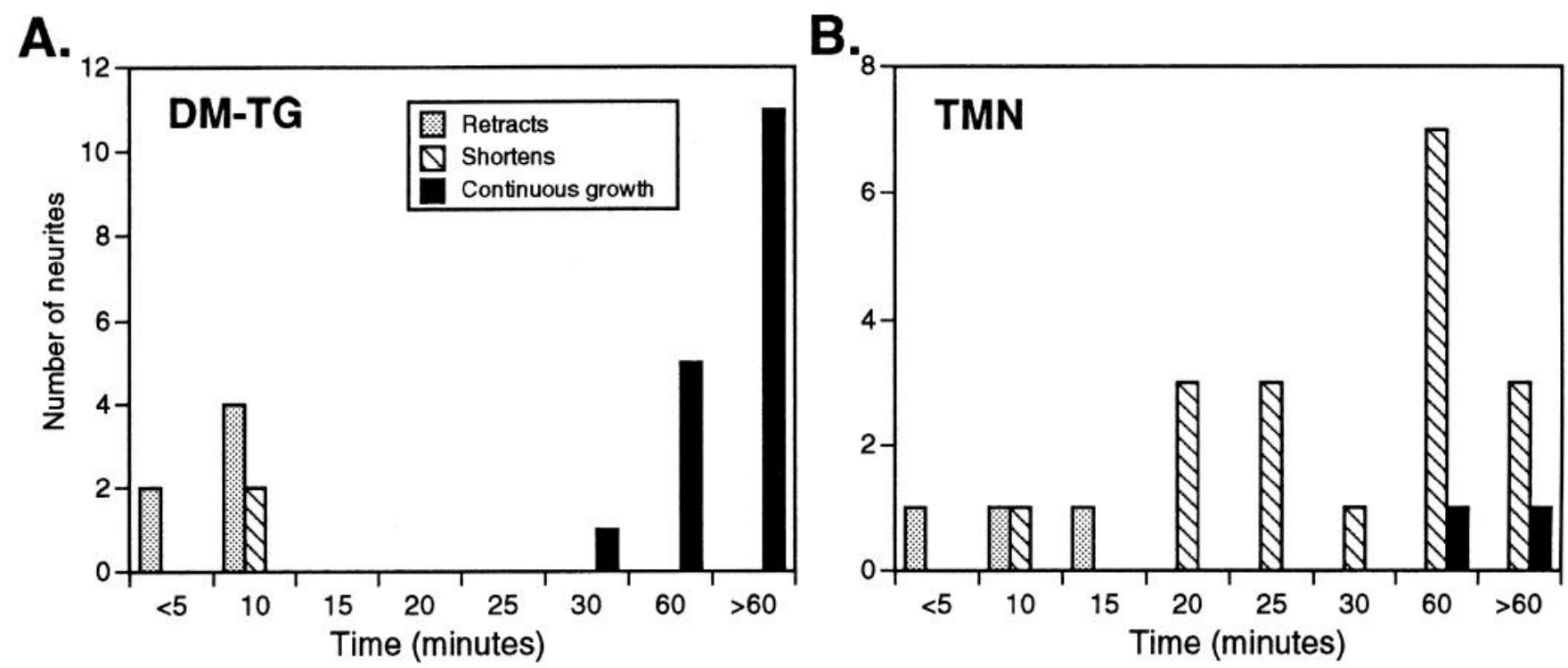

Figure 8. Bar graph summarizing the outcome of the initial encounters of $(A)$ cutaneous $(D M-T G)$ and $(B)$ muscle $(T M N)$ afferent growth cones with explants of dermis. Each chart shows the length of time that different neurites remained in contact with the dermis before retracting or beginning to shorten. For neurites that grew continuously and did not shorten, the time shown represents the duration of their growth on the dermis before recording was terminated. Most cutaneous neurites grew continuously across the dermis, whereas most muscle afferents retreated from the dermis. Three TMN growth cones that either grew across the dermis and onto the substrate or failed to grow on the dermis are excluded from this graph. For simplicity, only the highest time value of each bin is shown on the abscissa, as in Figure 3. 

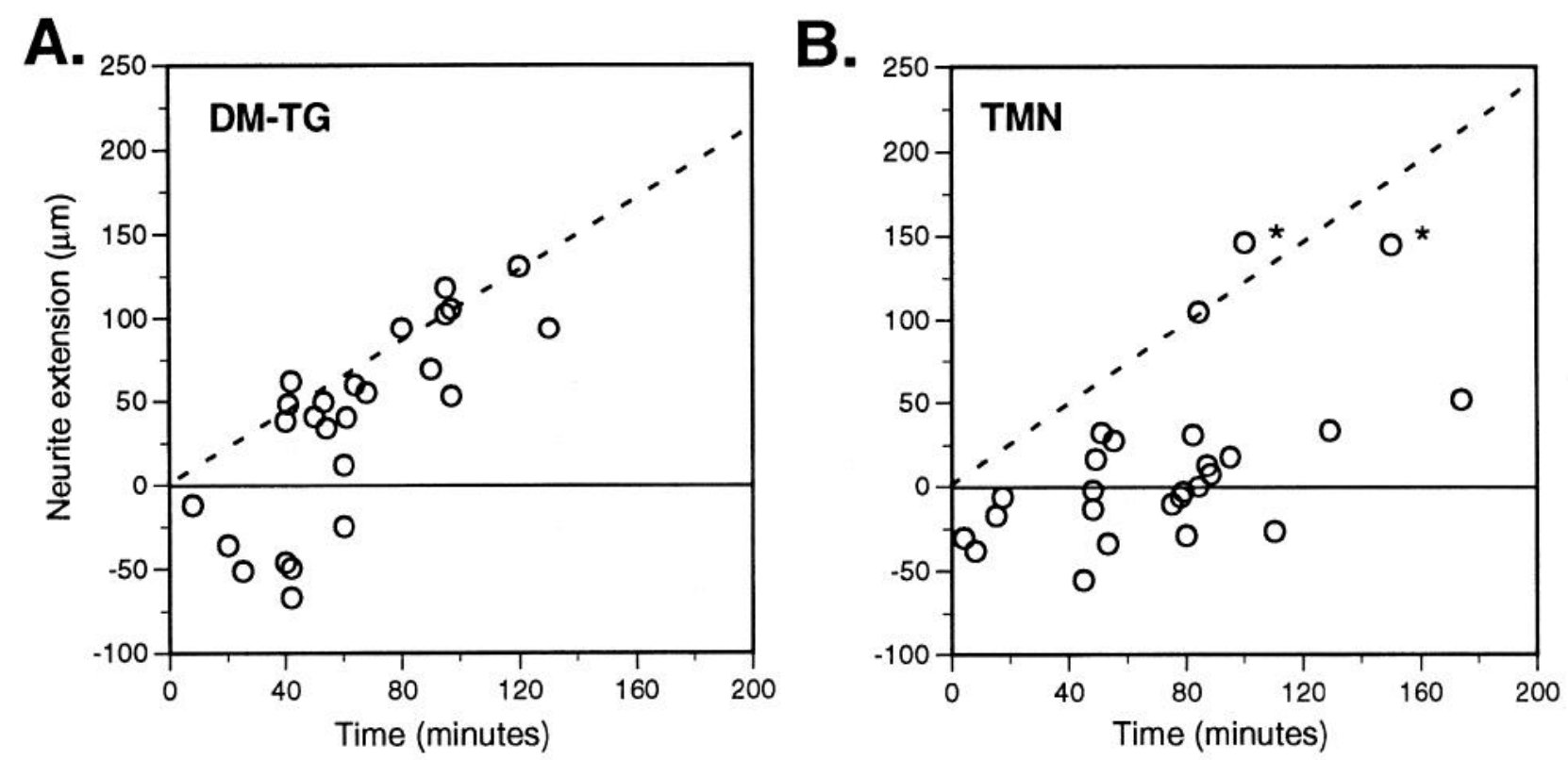

Figure 9. Comparison of real neurite growth on dermis with the theoretically predicted length. Open circles represent the length that $(A)$ DM-TG and $(B)$ TMN neurites grew from the time they first touched the edge of the dermis to the end of the recording session. This time interval is indicated on the abscissa. Dashed lines represent the linear regression curve for the theoretical lengths these neurons would have extended had their growth continued at the same rate as on the substrate. The two TMN growth cones marked by asterisks were growing on the substrate, rather than dermis, at the end the recording session. Note that many DM-TG, but very few TMN, neurites closely approximated their predicted lengths.

These discrepancies may reflect differences in experimental design. Both the age of the neurons and the culture substratum were different between this and previous studies. Second, we flooded our dishes with medium prior to recording, precluding analysis of diffusible inhibitory cues (Fichard et al., 1991; Pini, 1993). Moreover, we specifically selected for analysis growth cones that were growing directly toward the target. We cannot rule out the possibility, however, that neurites were responding to target-derived cues bound to the substrate (Gunderson, 1985). Third, muscle afferents may have been largely absent from DRG cultures supplemented only with NGF, which is relatively ineffective in supporting muscle afferents in vitro (Hory-Lee et al., 1993; LoPresti and Scott, 1994). Finally, DRG neurites were recorded at 5-15 min intervals (Verna, 1985; Verna et al., 1986), whereas trigeminal neurites frequently retracted within $5 \mathrm{~min}$ of touching an epidermal cell. This suggests that contacts between DRG neurites and epidermal explants may often have been missed in previous studies.
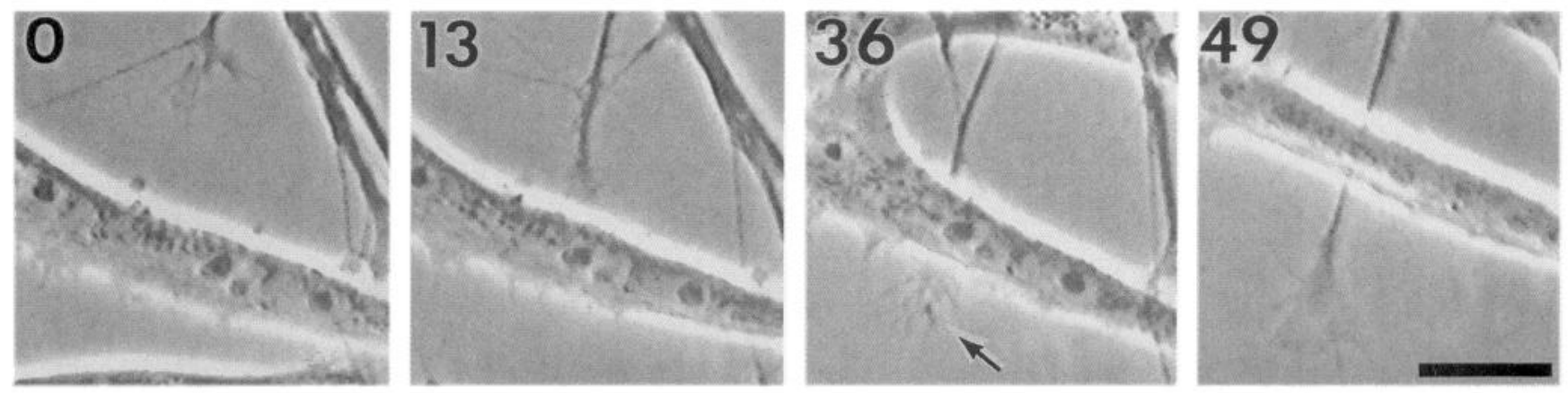

Figure 10. Time lapse records of an encounter between a DM-TG neurite with a myotube derived from the adductor mandibulae. The number in each panel represents the time $(\mathrm{min})$ at which the image was captured. The neurite contacted the myotube at approximately $t=15$ min, and grew across it with little change in direction or delay. Arrow at $t=36 \mathrm{~min}$ points to the growth cone as it leaves the myotube surface and begins to grow on the substrate again. Note that the field of view is shifted slightly at $t=49$ min. Scale bar, $20 \mu \mathrm{m}$. 

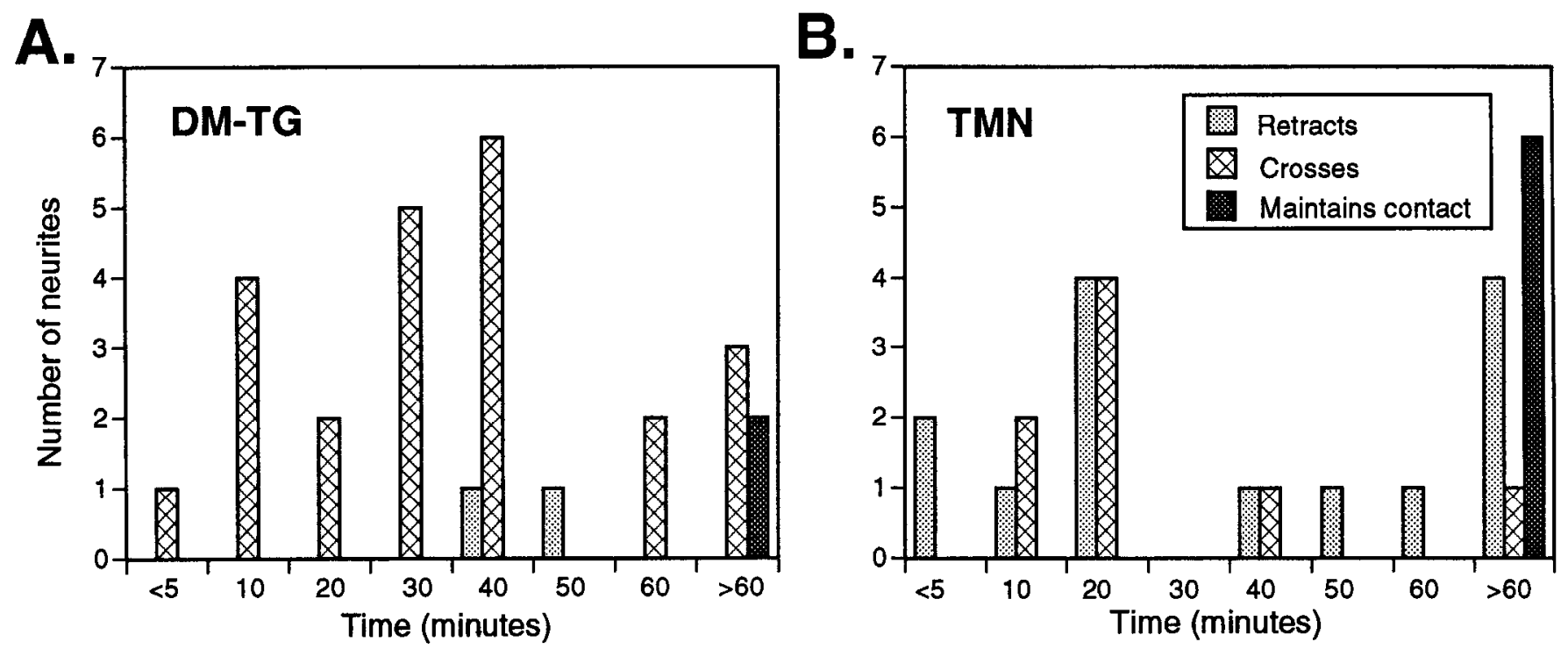

Figure 11. Bar graph summarizing the outcome of the initial encounters of $(A)$ cutaneous $(D M-T G)$ and $(B)$ muscle $(T M N)$ afferent growth cones with myotubes. Each chart shows the length of time that different neurites remained in contact with the myotube before retracting or growing off. Most cutaneous afferents crossed rapidly, and relatively few retracted or remained in contact during the time observed. In contrast, few muscle afferents crossed the myotube; most either retracted or remained in contact during the time observed. For simplicity, only the highest time value of each bin is shown on the abscissa, as in Figure 3.

cues and that stereotyped behaviors are not necessarily equivalent from one system to another. For example, upon encountering an appropriate target a growth cone may continue growing (e.g., cutaneous afferent-dermis interactions and some muscle afferent-myotube interactions, present study; see also Moorman and Hume, 1990) or stop growing as a prelude to synapse formation (Baird et al., 1992; Cooper and Smith, 1992). Alternatively, a growth cone may also stop growing upon encountering a cell that expresses inhibitory molecules (Bandtlow et al., 1990). Growth cone behaviors in vitro must, therefore, be interpreted within the context of the normal development of the system under study.

With this in mind, our studies indicate that trigeminal sensory neurites, like those in other systems, can selectively and appropriately respond in vitro to cells encountered during the course of normal development. For example, to reach their target skin in vivo, cutaneous afferents must grow past muscle masses composed of myotubes. Upon reaching the dermis, they ramify extensively, setting up the mature pattern of cutaneous innervation prior to the development of their target receptors, which they subsequently induce (Saxod, 1978); in birds, few axons penetrate into the epidermis (Saxod, 1978). The behavior of cutaneous afferents in vitro mirrors this pattern; cutaneous afferents grow readily over myotubes and dermis, but are repelled by epidermis. Similarly, outgrowing motor ncuron (Oakley and Tosney, 1993), sympathetic preganglionic (Moorman and Hume, 1990), cerebellar (Baird et al., 1992), and other axons can distinguish in vitro between appropriate and inappropriate cells that might be encountered along their in vivo pathways.

Whereas muscle afferents would not be expected to encounter skin in normal development, our in vitro observations suggest that muscle afferents recognize both dermis and epidermis as inappropriate, and respond to these cells with reduced growth. Thus, any muscle afferents that should stray into the dermis in vivo would soon be turned away. Similarly, cortical neurons fail to grow on inappropriate CNS regions that they would normally never encounter in vivo (Kuang et al., 1994).

Muscle afferents might be expected to occasionally grow across myotubes in vivo, as was observed in vitro, given the dispersed distribution of muscle spindles throughout muscle (Barker, 1974). However, because these afferents normally selectivcly interact with individual myotubes to induce the formation of muscle spindles (Milburn, 1984), a process that can occur throughout life (Mackenson-Dean et al., 1981; Kucera et al., 1993), we expected a priori that muscle afferents would establish stable contacts with myotubes in vitro, similar to those made by cerebellar (Baird et al., 1992) and hippocampal neurons (Cooper and Smith, 1992), but most did not. Possible reasons for this are discussed below.

We have interpreted our results as reflecting differences between cutaneous and muscle afferents. An alternative explanation is that they reflect differences between sensory neurons in the peripheral (DM-TG) and central nervous system (TMN), since some investigators have suggested that central and peripheral neurons express distinct surface labels that determine their in vitro behaviors (Kapfhammer and Raper, 1987). In contrast, findings from several other laboratories suggest that this twolabel hypothesis is insufficient to explain the diversity and specificity of growth cones behaviors observed in vitro (e.g., Walter et al., 1987; Ivins and Pittman, 1989; Moorman and Hume, 1990; Honig and Burden, 1993). Regardless of the underlying reasons, there are clear differences in behavior between DM-TG and TMN neurons, which each innervate targets in both the periphery and CNS.

\section{Variability among responses}

Although there were overall differences between the responses of trigeminal cutaneous and muscle afferents to all three potential targets, not all DM-TG or TMN neurons behaved identically upon encountering a particular type of target. For example, one- 

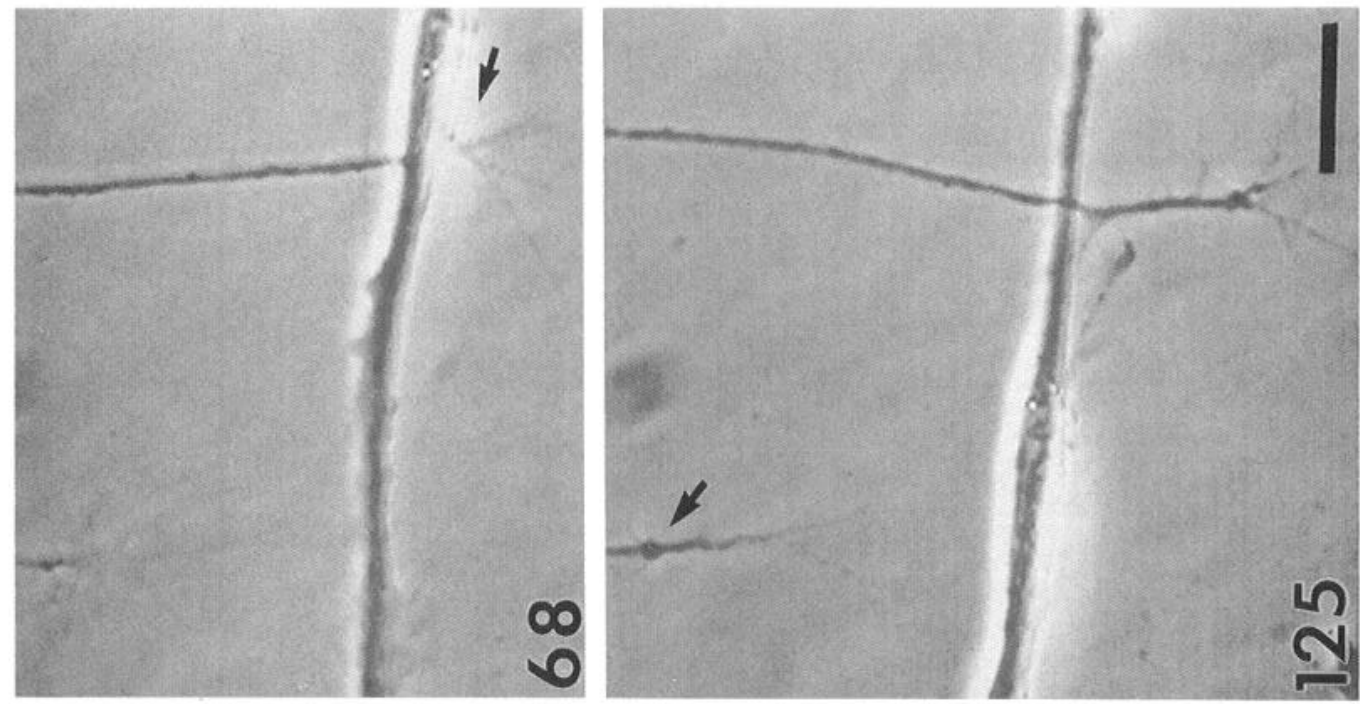

氙总

¿

异

๑

吾

氖哭

흔뭉

区

¿.

ริํํㄹ

$\Xi \infty$

है ।

है

点 す
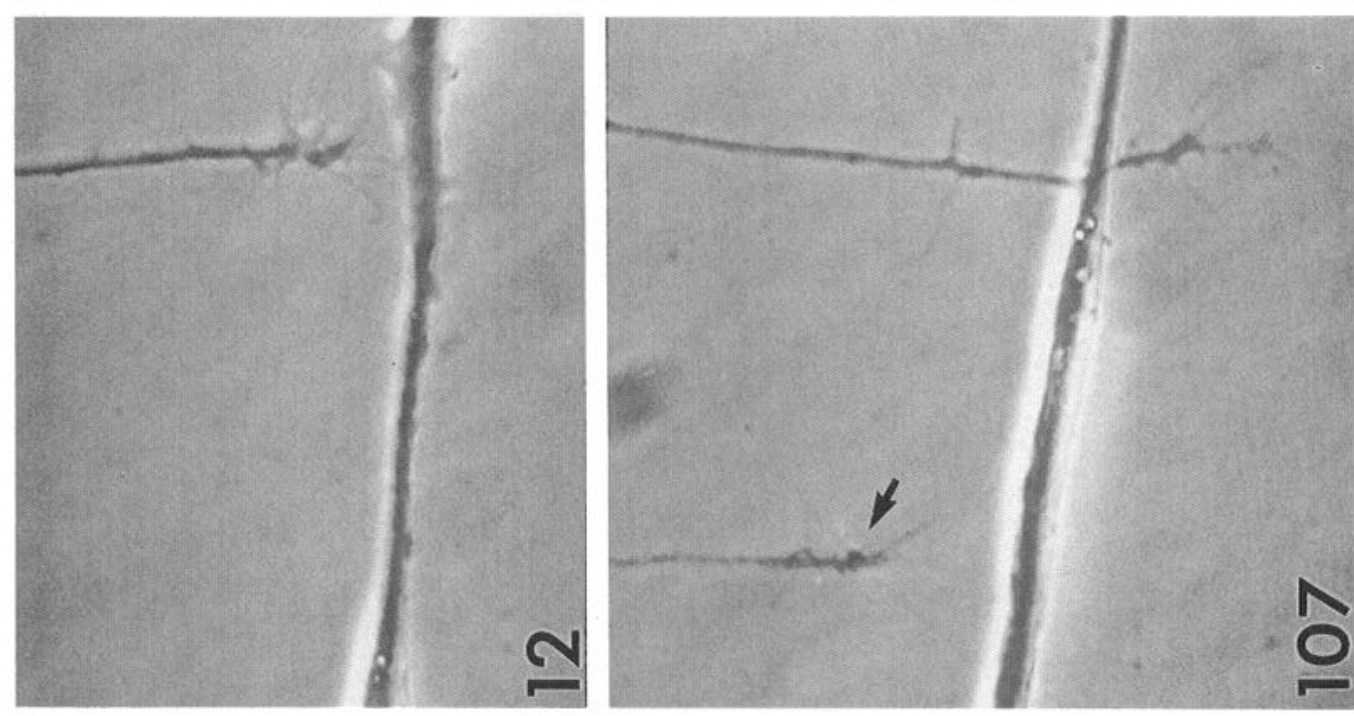

क् के 행요

늠

臣焏

ఫั

总

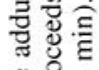

흘슬

힝

政

ญ ฏ

츤

है।

$\approx=0$

를 닌

के 등

氖志

ฮ ․ㅌ

之药京
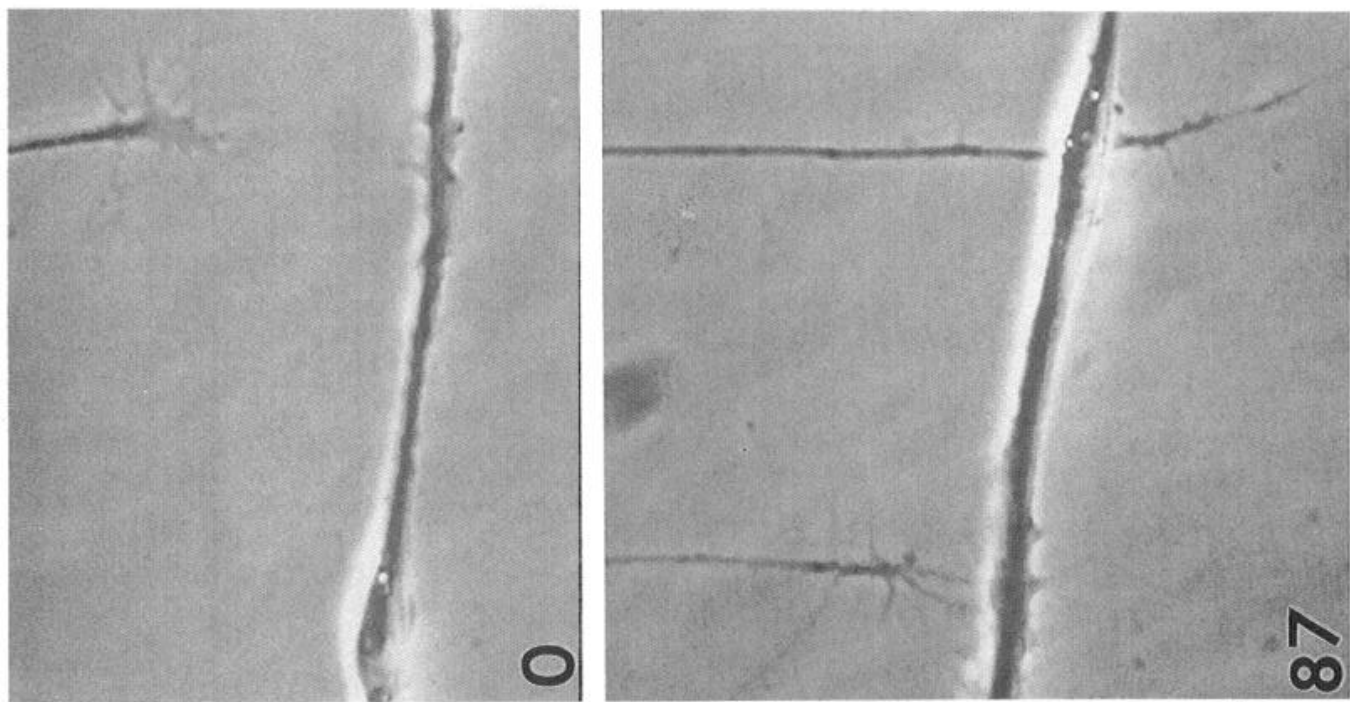

등

ญํ.

3ั

西-

늘

혼

䟻

पㄷ

की

링

ญ्త

ขึ

言 3

()

ह :

용 골 ․․․ 这娄 

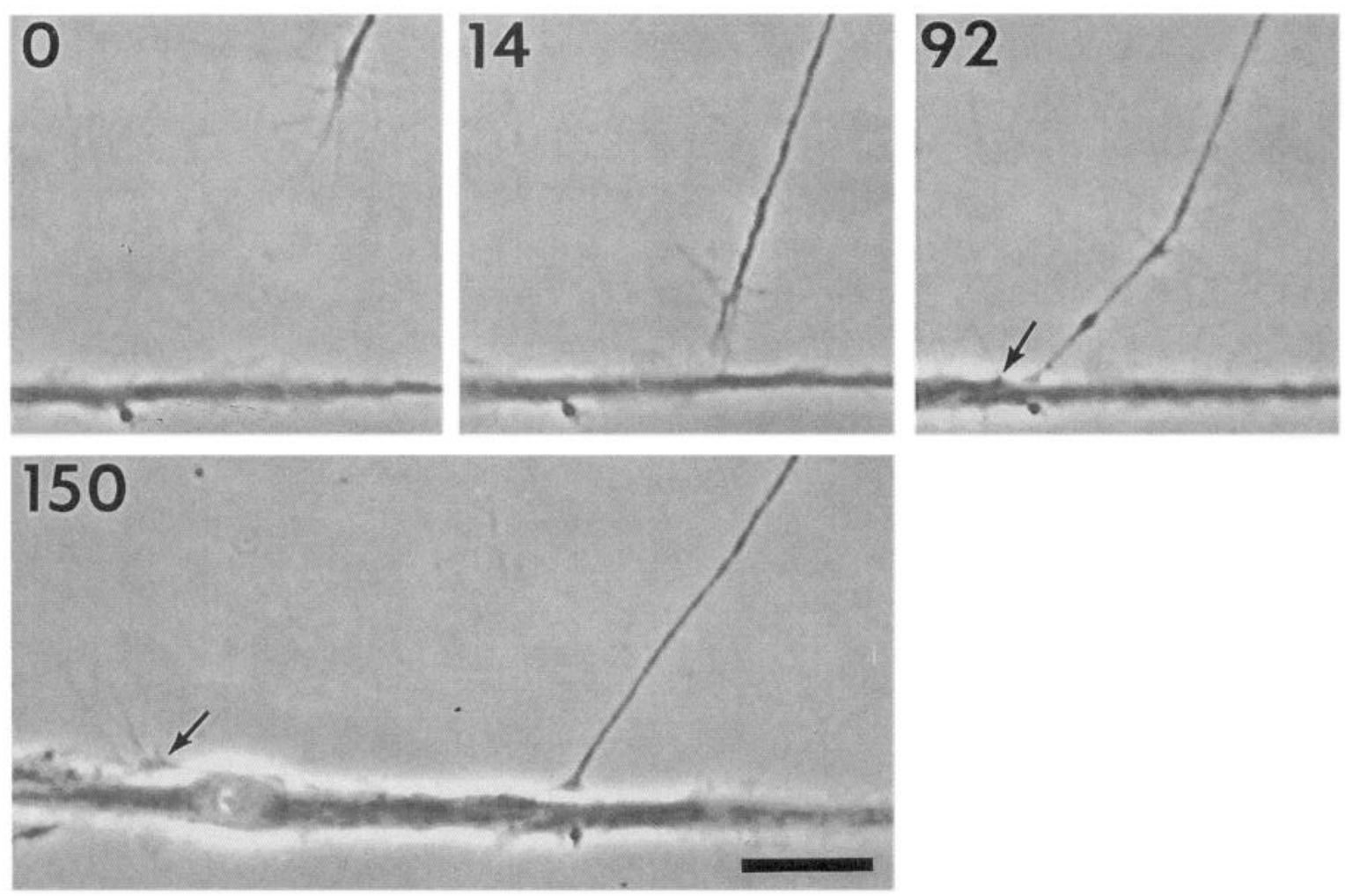

Figure 13. Time lapse records of an encounter between a TMN neurite and a myotube from the adductor mandibulae. The number in each panel represents the time $(\mathrm{min})$ at which the image was acquired. Note that this neurite changed direction after contacting the myotube and grew along it in close apposition. Arrows indicate the tip of the growth cone on the myotube. This particular myocyte may actually be a myoblast (i.e., mononuclear), however similar behavior was exhibited by other TMN neurites that encountered large, multinucleated myotubes. Scale bar, $20 \mu \mathrm{m}$.
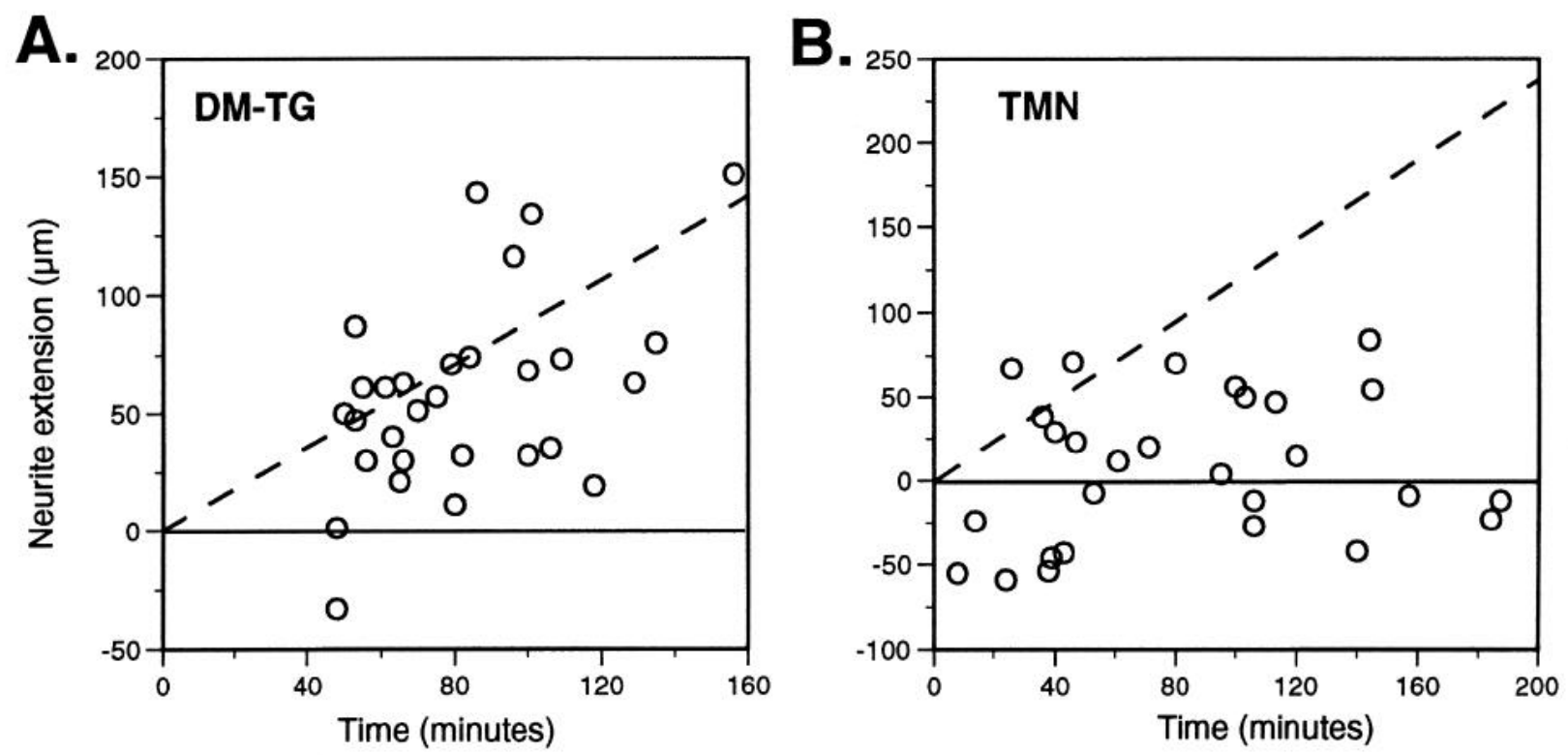

Figure 14. Comparison of actual neurite growth after contacting a myotube with the theoretically predicted length. Open circles represent the length that $(A)$ DM-TG and $(B)$ TMN neurites grew from the time they first contacted a myotube to the end of the recording session. This time interval is indicated on the abscissa. Dashed lines represent the linear regression curve for the theoretical lengths these neurons would have extended had their growth continued at the same rate as on the substrate prior to contact. Note that many DM-TG, but few TMN neurites closely approximated their predicted lengths. This reflects the fact that, overall, TMN neurites remained in contact with the myotube longer than DM-TG neurites. 
fourth of DM-TG neurites retracted upon contacting dermis, whereas most grew readily across the explant. Further, half of TMN neurons retracted from myotubes; the others either crossed or remained in contact. This variability most likely reflects heterogeneity within both the neuronal explants and the cocultured targets.

Heterogeneity among the neurons. Clearly both the DM-TG and TMN contain a mixture of neurons. For example, trigeminal neurons innervate a diversity of cutaneous sensory end organs (reviewed in Saxod, 1978), and the different types of afferents may interact differently with potential targets. Further, a few of the DM-TG neurons classified as cutaneous may have been muscle afferents, since the trigeminal ganglion is not purely cutaneous (Zeigler et al., 1975; Wild and Zeigler, 1980; von Bartheld and Bothwell, 1993). Thus, for example, the DM-TG neurite that remained in contact with epidermis, and the few that failed to grow across myotubes, may have actually been muscle rather that cutaneous afferents.

The TMN also contains a diversity of muscle afferents (see Jerge, 1963; Cody et al., 1972; Linden, 1978, for mammals), although physiological studies of the avian TMN have identified only spindle afferents (Manni et al., 1965; Passatore et al., 1979). However, these studies most likely underestimated avian TMN heterogeneity, as TMN neurons in hatchling chicks are strikingly diverse immunohistochemically (Scott et al., 1994b). For example, approximately $40 \%$ of medial TMN neurons are relatively small, substance $\mathrm{P}$-positive, presumably nociceptive, neurons. Since these are likely to terminate in muscle as free nerve endings (Hunt et al., 1992), they might not form stable contacts with myotubes, either in vivo or in vitro. Importantly, because spindles are induced exclusively by. Ia afferents (e.g., Kucera and Walro, 1993), perhaps only this subpopulation of muscle afferents would be expected to selectively associate with myotubes in vitro.

We do not know the percentage of Ia afferents in our TMN cultures. Although these cultures were supplemented with BDNF, which supports more than $80 \%$ of avian TMN neurons in vitro (Davies et al., 1986), recent studies of knockout mice suggest that Ia afferents require neurotrophin-3 for survival in vivo (reviewed in Snider, 1994). However, because TMN neurons were cultured with target myotubes (as well as neighboring glial cells), which should provide additional trophic support, it is likely that a substantial fraction of the normal number of Ia afferents were present.

Heterogeneity within the target population. A second source of variability is microheterogeneity within the cocultured targets. For example, embryonic avian dermis has regionally specific morphogenetic properties that determine the character and distribution of sensory receptors (reviewed in Saxod, 1978). Moreover, feather-forming skin produces a constellation of extracellular matrix and cell surface molecules distributed in a complex pattern (Mauger et al., 1983; Jahoda et al, 1987; Kitamura, 1987; Sengel, 1990; Fichard et al., 1991; Jiang and Chuong, 1992). Whercas these constituents have been implicated in the induction and differentiation of feathers and scales, they also appear to regulate axon growth (Carbonetto et al., 1982; Rogers et al., 1983; Verna et al., 1989; Snow et al., 1990). The response of a sensory afferent to dermis or epidermis may be determined in part, therefore, by the regional characteristics of the explant, including the relative amounts of inhibitory and permissive molecules expressed on the individual cells encountered.

Our myotube cultures are also likely to be heterogeneous.
Myoblasts constitute an extremely diverse progenitor pool (reviewed in Stockdale and Miller, 1987; Miller, 1992). The identity of myotubes in our cultures is unknown, although "fetal" and "adult" lineages of secondary myotubes should be equally represented (Feldman and Stockdale, 1992). Importantly, whether intrafusal fibers arise from a discrete lineage of myotubes $(\mathrm{Ku}-$ cera et al., 1989; Thornell and Pedrosa, 1990; Kucera and Walro, 1993), or alternatively, all myotubes are equipotent (Kucera, 1990; Kucera and Walro, 1990) is unresolved. The existence of a discrete class of spindle-forming myotubes would help to explain the observed variability in TMN behavior. That is, muscle afferents may be able to recognize distinctions among myotubes, and find only a small percentage acceptable; that most TMN neurites either reject or stick to myotubes is consistent with this possibility. However, since the responses of different TMN neurites to the same myotube could vary (e.g., Fig. 12), myotube heterogeneity alone cannot account entirely for the observed variability among TMN neurites, some of which is undoubtedly intrinsic to the neurons themselves (above).

\section{Implications for normal development and/or regeneration}

Since trigeminal sensory neurons extend axons to their respective targets prior to embryonic day 10 (Moody et al., 1989; von Barthcld and Bothwcll, 1993), our findings demonstrate differences in growth cone behavior during regeneration, rather than initial outgrowth, of embryonic sensory axons. A key question is whether these differences in growth cone behavior are also expressed by naive sensory axons en route to their targets for the first time. At the stages studied, DM-TG and TMN neurons express different levels of several surface adhesion molecules (Halfter el al., 1994; Scoll el al., 1994a; see also Honig and Kueter, 1995, for DRG neurons) that could govern the behaviors reported here. Developmental regulation of such surface recognition molecules is well documented (Edelman, 1984; Dodd et al., 1988; Reichardt, 1992). Additional experiments involving neurons from younger embryos that have not yet contacted their targets will be required to determine whether the observed differences between DM-TG and TMN neurons develop as a consequence of target innervation, or instead represent fundamental differences between these cutaneous and muscle afferent neurons. As such they would be available to play a role in the selection of axonal pathways or targets during normal embryonic development.

\section{References}

Baird DH, Hatten ME, Mason CA (1992) Cerebellar target neurons provide a stop signal for afferent neurite extension in vitro. $\mathrm{J}$ Neurosci 12:619-634.

Bandtlow C, Zachleder T, Schwab ME (1990) Oligodendrocytes arrest neurite growth by contact inhibition. J Neurosci 10:3837-3848.

Barker D (1974) The morphology of muscle receptors. In: Handbook of sensory physiology, Vol 3 (Hunt CC, ed), pp 1-190. New York: Springer

Bottenstein JE, Skaper SD, Varon SS, Sato GH (1980) Selective survival of neurons from chick embryo sensory ganglionic dissociates utilizing serum-free supplemented medium. Exp Cell Res 125:183190.

Carbonetto ST, Gruver MM, Turner DC (1982) Nerve fiber growth on defined hydrogel substrates. Science 216:897-899.

Cody FWJ, Lee RWH, Taylor A (1972) A functional analysis of the components of the mesencephalic nucleus of the fifth nerve in the cat. J Physiol (Lond) 226:249-261.

Cooper MW, Smith SJ (1992) A real-time analysis of growth conetarget cell interactions during the formation of stable contacts between hippocampal neurons in culture. J Neurobiol 23:814-828. 
Copray JCVM, Liem RSB (1993) Survival and neurite formation of mesencephalic trigeminal neurones of the rat in vitro. Arch Oral Biol 38:547-557.

Covell DA Jr, Noden DM (1989) Embryonic development of the chick primary trigeminal sensory-motor complex. J Comp Neurol 286:488503.

D'Amico-Martel A, Noden DM (1983) Contributions of placodal and neural crest cells to avian cranial peripheral ganglia. Am J Anat 166: $445-468$.

Davies A, Lindsay RM (1984) Neural crest-derived spinal and cranial sensory neurones are equally sensitive to NGF but differ in their response to tissue extracts. Dev Brain Res 14:121-127.

Davies AM (1989) Neurotrophic factor bioassay using dissociated neurons. In: Nerve growth factors (Rush RA, ed), pp 95-109. New York: Wiley.

Davies AM, Thoenen H, Barde Y-A (1986) The response of chick sensory neurons to brain-derived neurotrophic factor. J Neurosei 6:1897-1904.

Dodd J, Morton SB, Karagogeos D, Yamamoto M, Jessell TM (1988) Spatial regulation of axonal glycoprotein expression on subsets of embryonic spinal neurons. Neuron 1:105-116.

Edelman GM (1984) Modulation of cell adhesion during induction, histogenesis, and perinatal development of the nervous system. Annu Rev Neurosci 7:339-377.

Feldman JL, Stockdale FE (1992) Temporal appearance of satellite cells during myogenesis. Dev Biol 153:217-226.

Fichard A, Verna J-M, Olivares J, Saxod R (1991) Involvement of a chondroitin sulfate proteoglycan in the avoidance of chick epidermis by dorsal root ganglia fibers: a study using $\beta$-D-xyloside. Dev Biol 148:1-9.

Gundersen RW (1985) Sensory neurite growth cone guidance by substrate adsorbed nerve growth factor. I Neurosci 13:199-212.

Halfter W, Yip YPL, Yip JW (1994) Axonin 1 is expressed primarily in subclasses of avian sensory neurons during outgrowth. Dev Brain Res 78:87-101.

Hamburger V, Hamilton HL (1951) A series of normal stages in the development of the chick embryo. J Morphol 88:49-92.

Heaton MB, Wayne DB (1986) Specific responsiveness of chick trigeminal motor nucleus explants to target-conditioned media. J Comp Neurol 243:381-387.

Hiscock J, Straznicky C (1986) The formation of axonal projections of the mesencephalic trigeminal neurons in chick embryos. $J$ Embryol Exp Morphol 93:281-290.

Honig MG (1982) The development of sensory projection patterns in embryonic chick hind limb. J Physiol (Lond) 330:175-202.

Honig MG, Burden SM (1993) Growth cones respond in diverse ways upon encountering neurites in cultures of chick dorsal root ganglia. Dev Biol 156:454-472.

Honig MG, Kueter J (1995) The expression of adhesion molecules on the growth cones of chick cutaneous and muscle sensory neurons. Dev Biol, in press.

Hory-Lee F, Russell M, Lindsay RM, Frank E (1993) Neurotrophin 3 supports the survival of developing muscle sensory neurons in culture. Proc Natl Acad Sci USA 90:2613-2617.

Hunt SP, Mantyh PW, Priestly JV (1992) The organization of biochemically characterized sensory neurons. In: Sensory neurons: diversity, development, and plasticity (Scott SA, ed), pp 60-76. New York: Oxford UP.

Ivins JK, Pittman RN (1989) Growth cone-growth cone interactions in cultures of rat sympathetic neurons. Dev Biol 135:147-157.

Jahoda CAB, Mauger A, Sengel P (1987) Histochemical localization of skin glycosaminoglycans during feather development in the chick embryo. Dev Biol 196:303-315.

Jerge CR (1963) Organization and function of the trigeminal mesencephalic nucleus. J Physiol (Lond) 26:379-392.

Jiang T-X, Chuong C-M (1992) Mechanism of skin morphogenesis. I. Analyses with antibodies to adhesion molecules tenascin, N-CAM, and integrin. Dev Biol 150:82-98.

Kapfhammer JP, Raper JA (1987) Interactions between growth cones and neurites growing from different neural tissues in culture. J Neurosci 7:1595-1600.

Kitamura K (1987) The structure and distribution of proteochondroitin sulphate during the formation of chick embryo fether germs. Development 100:501-512.

Kuang RZ, Merline M, Kalil K (1994) Topographic specificity of cor- ticospinal connections formed in explant coculture. Development 120:1-11

Kucera J (1990) Regulation of the development of mammalian muscle spindles. J Neurol Sci 98:47.

Kucera J, Walro JM (1990) Origin of intrafusal muscle fibers in the rat. Histochemistry 93:567-580.

Kucera J, Walro JM (1993) Transient expression of a slow-tonic MHC isoform by extrafusal fibers in the developing rat. Anat Embryol 188: $409-418$

Kucera J, Walro JM, Reichler J (1989) Role of nerve and muscle factors in the development of rat muscle spindles. Am J Anat 186:144 160.

Kucera J, Walro JM, Gao Y (1993) Influence of muscle cell substrates on differentiation of intrafusal fiber types in neonatal rats. Neuroscience 52:1001-1008.

Landmesser L, Honig MG (1986) Altered sensory projections in the chick hind limb following the early removal of motoneurons. Dev Biol 118:511-531.

Linden RWA (1978) Properties of intraoral mechanoreceptors represented in the mesencephalic nucleus of the fifth nerve in the cat. $J$ Physiol (Lond) 279:395-408.

LoPresti P, Scott SA (1994) Target specificity and size of avian sensory neurons supported in vitro by NGF, BDNF, and NT-3. J Neurobiol $25: 1613-1624$

Lumsden AGS, Davies AM (1983) Earliest sensory nerve fibers are guided by attractants other than nerve growth factor. Nature 306:786788 .

Lumsden AGS, Davies AM (1986) Chemotropic effect of specific target epithelium in the developing mammalian nervous system. Nature 323:538-539.

Mackenson-Dean CA, Hikida RS, Frangowlakis TM (1981) Formation of muscle spindles in regenerated avian muscle grafts. Cell Tissue Res 217:37-41.

Manni E, Bortolami R, Azzena GB (1965) Jaw muscle proprioception and mesencephalic trigeminal cells in birds. Exp Neurol 12:320-328.

Mauger A, Demarchez M, Herbage D, Grimaud J-A, Druguet M, Hartmann DJ, Foidart J-M, Sengel P (1983) Immunofluorescent localization of collagen types I, III, IV, fibronectin, and laminin during morphogenesis of scales and scaleless skin in the chick embryo. Rouxs Arch Dev Biol 192:205-215.

Milburn A (1984) Stages in the development of cat muscle spindles. J Embryol Exp Morphol 82:177-216.

Miller JB (1992) Myoblast diversity in skeletal myogenesis: how much and to what end? Cell 69:1-3.

Moody SA, Quigg MS, Frankfurter A (1989) Development of the peripheral trigeminal system in the chick revealed by an isotype-specific anti-beta-tubulin monoclonal antibody. J Comp Neurol 279:567-580.

Moorman SJ, Hume RI (1990) Growth cones of chick sympathetic preganglionic neurons in vitro interact with other neurons in a cellspecific manner. J Neurosci 10:3158-3163.

Narayanan CH, Narayanan Y (1978) Determination of the embryonic origin of the mesencephatic nucleus of the trigeminal nerve in birds. J Embryol Exp Morphol 43:85-105.

Noden DM (1980) Somatotopic and functional organization of the avian trigeminal ganglion: an HRP analysis in the hatchling chick. $\mathbf{J}$ Comp Neurol 190:405-428.

Oakley RA, Tosney KW (1993) Contact-mediated mechanisms of motor axon segmentation. J Neurosci 13:3773-3792.

Passatore M, Bortolami R, Manni E (1979) Somatotopic arrangement of the proprioceptive afferents from the jaw muscles in the mesencephalic trigeminal nucleus of the duck. Arch ital Biol 117:123-139.

Pini A (1993) Chemorepulsion of axons in the developing mammalian central nervous system. Science 261:95-98.

Prives JAB, Fulton S, Penman S, Daniels MP, Christian CN (1987) Interaction of the cytoskeletal framework with acetylcholine receptor on the surface of embryonic muscle cells in culture. J Cell Biol 92: 231-236.

Reichardt LF (1992) Adhesive interactions that regulate neuronal behavior. In: Sensory neurons: diversity, development and plasticity (Scott SA, ed), pp 215-241. New York: Oxford UP.

Rogers SL, Letourneau PC, Palm SL, McCarthy J, Furcht LT (1983) Neurite extension by peripheral and central nervous system neurons in response to substratum-bound fibronectin and laminin. Dev Biol 98:212-220.

Saxod R (1978) Development of cutaneous sensory receptors in birds. 
In: Handbook of sensory physiology (Jacobson M, ed), pp 338-410. New York: Springer.

Scott SA (1988) Skin sensory innervation patterns in embryonic chick hindlimbs deprived of motoneurons. Dev Biol 126:362-374.

Scott SA (1992a) Cutaneous and muscle afferents: interactions with potential target tissues in vitro. Soc Neurosci Abstr 18:1274

Scott SA (1992b) The development of peripheral sensory innervation patterns. In: Sensory neurons: diversity, development, and plasticity (Scott SA, ed), pp 242-263. New York: Oxford IrP.

Scott SA, Chau CA, Randazzo KF (1994a) Cutaneous and muscle afferents: differential expression of adhesion molecules in vitro. Soc Neurosei Abstr 20: in press.

Scott SA, Dinowitz S, TerHaar K, Sherlock D, Campbell MA, LeVine D (1994b) Cytochemical characteristics of neurons in the trigeminal mesencephalic nucleus of hatchling chicks. J Comp Neurol 350:302310.

Sengel P (1990) Pattern formation in skin development. Int J Dev Biol 34:33-50.

Snider WD (1994) Functions of the neurotrophins during nervous system development: what the knockouts are teaching us. Cell 77:627638.

Snow DM, Lemmon F, Carrino DA, Caplan AI, Silver J (1990) Sulfated proteoglycans in astroglial barriers inhibit neurite outgrowth in vitro. Exp Neurol 109:111-130.

Stockdale FE, Miller JB (1987) The cellular basis of myosin heavy chain isoform expression during development of avian skeletal muscles. Dev Biol 123:1-9.

Thornell L-E, Pedrosa F (1990) Development of muscle spindles in- volves special myogenic cell lineage and neurogenic influence. J Neurol Sci 98:46.

Tosney KW, Hageman MS (1989) Different subsets of axonal guidance cues are essential for sensory neuritc outgrowth to cutancous and muscle targets in the dorsal ramus of the embryonic chick. J Exp Zool 251:232-244.

Verna J-M (1985) In vitro analysis of interactions between sensory neurons and skin: evidence for selective innervation of dermis and epidermis. J Embryol Exp Morphol 86:53-70.

Verna J-M, Usson Y, Saxod R (1986) Differential growth of sensory neurons in vitro in presence of dermis and epidermis. A quantitative time-lapse analysis. Cell Differ 18:183-188.

Verna J-M, Fichard A, Saxod R (1989) Influence of glycosaminoglycans on neurite morphology and outgrowth patterns in vitro. Int $\mathrm{J}$ Dev Neurosci 7:389-399.

von Bartheld CS, Bothwell M (1993) Development of the mesencephalic nucleus of the trigeminal nerve in chick embryos: target innervation, neurotrophin receptors, and cell death. J Comp Neurol 328:185-202.

Walter J, Henke-Fahle S, Bonhoeffer F (1987) Avoidance of posterior tectal membranes by temporal retinal axons. Development 101:909913.

Wild JM, Zeigler HP (1980) Central representation and somatotopic organization of the jaw muscles within the facial and trigeminal nuclei of the pigeon (Columba livia). J Comp Neurol 192:175-201.

Woodbury CJ, Scott SA (1994) Cutaneous and muscle afferents: interactions with myotubes in vitro. Soc Neurosci Abstr 20:656.

Zeigler HP, Miller M, Levine RR (1975) Trigeminal nerve and eating in the pigeon (Columbia livia): neurosensory control of the consummatory responses. J Comp Physiol Psychol 89:845-858. 